\author{
RESEARCH ARTICLE \\ 10.1029/2018JC014585 \\ Key Points: \\ - Wind stresses in shallow coastal \\ plain estuaries depend on wave age, \\ bathymetry, and fetch \\ - Subtidal bay-ocean exchange is \\ modulated by wind waves, wind \\ direction, tidal residual flows, and \\ wind-driven Stokes drift \\ - Wave breaking forces in a \\ swell-sheltered bay were negligible \\ except on shallow, steeply sloping \\ ridges
}

Correspondence to:

L. F. Pareja-Roman,

pareja@marine.rutgers.edu

Citation:

Pareja-Roman, L. F., Chant, R. J., \& Ralston, D. K. (2019). Effects of locally generated wind waves on the momentum budget and subtidal exchange in a coastal plain estuary. Journal of Geophysical Research: Oceans, 124, 1005-1028. https://doi. org/10.1029/2018JC014585

Received 18 SEP 2018 Accepted 23 JAN 2019 Accepted article online 28 JAN 2019 Published online 12 FEB 2019

(c)2019. American Geophysical Union. All Rights Reserved.

\section{Effects of Locally Generated Wind Waves on the Momentum Budget and Subtidal Exchange in a Coastal Plain Estuary}

\author{
L. Fernando Pareja-Roman ${ }^{1}$ (D), Robert J. Chant ${ }^{1}$ (D), and David K. Ralston ${ }^{2}$ (D) \\ ${ }^{1}$ Department of Marine and Coastal Sciences, Rutgers University, New Brunswick, NJ, USA, ${ }^{2}$ Applied Ocean Physics and \\ Engineering Department, Woods Hole Oceanographic Institution, Woods Hole, MA, USA
}

\begin{abstract}
A numerical model with a vortex force formalism is used to study the role of wind waves in the momentum budget and subtidal exchange of a shallow coastal plain estuary, Delaware Bay. Wave height and age in the bay have a spatial distribution that is controlled by bathymetry and fetch, with implications for the surface drag coefficient in young, underdeveloped seas. Inclusion of waves in the model leads to increases in the surface drag coefficient by up to $30 \%$ with respect to parameterizations in which surface drag is only a function of wind speed, in agreement with recent observations of air-sea fluxes in estuaries. The model was modified to prevent whitecapping wave dissipation from generating breaking forces since that contribution is integrally equivalent to the wind stress. The proposed adjustment is consistent with previous studies of wave-induced nearshore currents and with additional parameterizations for breaking forces in the model. The mean momentum balance during a simulated wind event was mainly between the pressure gradient force and surface stress, with negligible contributions by vortex, wave breaking (i.e., depth-induced), and Stokes-Coriolis forces. Modeled scenarios with realistic Delaware bathymetry suggest that the subtidal bay-ocean exchange at storm time scales is sensitive to wave-induced surface drag coefficient, wind direction, and mass transport due to the Stokes drift. Results herein are applicable to shallow coastal systems where the typical wave field is young (i.e., wind seas) and modulated by bathymetry.
\end{abstract}

Plain Language Summary Water circulation and pollutant flushing in estuaries, bays, and similar coastal environments depend mainly on tidal currents, winds, and density differences between fresh and saltwater. However, winds normally coexist with waves, and the impact of waves on circulation patterns is often overlooked in most numerical models. In this study we used a numerical model to explore how Delaware Bay responds to a typical storm event. The model was configured to consider or ignore the effects of waves on circulation, and we used both options to contrast and compare the simulated results. The model that ignored waves could not reproduce the mechanisms that have been shown to control the energy transfer from the atmosphere to the water column. In agreement with recent observations in estuaries, the model indicates that wind waves in shallow water have an important regulating effect on the roughness of the sea surface, which is key for surface drag and circulation. We also report that even when the wind speed is the same above the water surface, the spatial distribution of waves determines the effective amount of energy that gets transferred from the air to the water column.

\section{Introduction}

The dynamics of shallow bays are mainly governed by the interaction of density gradients and tides, but episodic wind events can also have an important role in flushing and circulation (Geyer, 1997; Scully et al., 2005; Whitney \& Codiga, 2011). Studies of wind-driven circulation in systems such as lakes provide insight into how estuaries can respond to wind events. In a large lake, Csanady (1973) found that axial winds led to a laterally sheared flow with a downwind current in shallow water and return flow over deeper regions. In the case of rotating basins with more complicated (e.g., multichannel) bathymetry, the Coriolis effect can introduce transverse circulation in the form of gyres and lead to asymmetries in the upwind and downwind currents (Sanay \& Valle-Levinson, 2005). Rotation-induced flow asymmetries in estuaries can develop in response to Ekman straining through the lateral advection of the along-channel momentum (Scully et al., 2009). Winds can also induce dynamic responses in estuaries through nonlocal effects. For example, alongshore winds on the shelf can drive Ekman transport into or out of bays, leading to 
adjustments in the subtidal sea level as observed in Delaware Bay (Wong \& Garvine, 1984). A simple barotropic model of shelf-estuary coupling reveals that such a response to remote winds is significant when estuaries are short relative to subtidal elevation wavelengths, which can be up to 10 times the typical basin length (Garvine, 1985; Henrie \& Valle-Levinson, 2014).

Although the aforementioned contributions to the literature denote an initial success in understanding the effects of local and remote wind stresses on circulation in shallow bays, an aspect that is often overlooked is the impact of local, wind-generated waves on circulation and boundary layer drag. For example, Signell et al. (1990) reported that wind-driven flushing in a long embayment is modulated by near-bed wave-current interactions, but the wave field considered in that study was prescribed and uniform instead of windgenerated. Similarly, Bricker et al. (2004) used a model with wave-current interactions in the bottom layer to study the impact of waves and circulation in San Francisco Bay but considered no feedback between waves and surface drag. In terms of hurricanes in coastal plain estuaries, M. Li et al. (2006) reported the impact of storm surges on the layered circulation in Chesapeake Bay and omitted wind-wave forcing in the model. The mechanisms of wave generation and dissipation are now relatively well understood and have informed the creation of coupled wave and circulation models (Warner et al., 2008), whose output can be used to fully assess the impact of wind generated waves on shallow water circulation. In the following sections, we describe how waves may play a role in the transfer of energy, mass, and momentum across the airsea and bed interfaces, as well as through the water column with a focus on implications for the momentum budget and subtidal exchange in coastal plain estuaries.

\subsection{Surface Layer}

At the surface layer, wind waves influence the mechanical coupling between the ocean and the atmosphere by altering the surface drag coefficient for the wind stress, the energy transfer from winds to the wave field, and the injection of turbulence. The drag coefficient $\left(C_{D}\right)$ that is used to calculate wind stress $\left(\tau_{s}\right)$ is often expressed as a function of wind speed at a reference height of $10 \mathrm{~m}\left(U_{10}\right)$. The established bulk formula for the wind stress magnitude in a neutrally stable atmosphere takes the form $\tau_{s}=\rho_{\mathrm{a}} C_{D} U_{10}^{2}$ where $\rho_{\mathrm{a}}$ is the air density. Examples of widely used parameterizations for $C_{D}$ include the works of Wu (1982) and Large and Pond (1981) in which the drag coefficient is proportional to the wind speed. Following those and other studies, significant advances in understanding air-sea momentum fluxes resulted from the Tropical Ocean Global Atmosphere, Coupled Ocean Atmosphere Response Experiment program (Fairall et al., 1996). The extensive data sets from those experiments improved the parameterizations for $C_{D}$ and retained the general trend wherein drag increases with $U_{10}$; see, for example, the Coupled Ocean Atmosphere Response Experiment (COARE) 3.0 and 3.5 algorithms (Edson et al., 2013; Fairall et al., 2003).

Parallel to the developments of Tropical Ocean Global Atmosphere, Coupled Ocean Atmosphere Response Experiment, other authors reported that calculating $C_{D}$ based on wind speed alone may be inadequate since drag is also communicated by the spatially variable sea surface roughness, which depends on factors such as fetch, wave phase speed, and wind duration (Drennan et al., 2005). Accounting for these details can be achieved by expressing the drag coefficient as a function of the surface roughness length $\left(z_{0}\right)$ as $C_{D}=(\kappa)$ $\left.\ln \left(z_{\text {ref }} / z_{0}\right)\right)^{2}$, where $x$ is the von-Karman constant and $z_{\text {ref }}$ is a reference height above the surface. For the previous $C_{D}$ expression, $z_{0}=z_{\mathrm{s}}+z_{\mathrm{r}}$, where $z_{\mathrm{s}}$ and $z_{\mathrm{r}}$ are the smooth and rough (turbulent) components of surface roughness. The rough contribution can be expressed as (Charnock, 1955)

$$
z_{\mathrm{r}}=\alpha \frac{u_{*}^{2}}{g}
$$

where $\alpha$ is referred to as Charnock's alpha, $u_{*}=\sqrt{\tau_{s} / \rho_{\mathrm{a}}}$ is the surface shear velocity, and $g$ is the gravitational acceleration. Kitaigorodskii (1973) and later other authors (Johnson \& Vested, 1992; Oost et al., 2002) proposed that the effect of both winds and waves on roughness can be accounted for by making $\alpha$ depend on the wave age, or the ratio between the wave phase speed and the surface shear velocity, $c_{p} / u_{*}$. One of the advantages of considering the wave age to model Charnock's alpha is that it incorporates the roughness' sensitivity to depth, fetch, and duration, which may not be appropriately captured by the bulk wind speed (Fisher et al., 2015). As will be shown later, the wave age in shallow, fetch limited environments is typical of underdeveloped young seas $\left(c_{p} / u_{*}<33\right.$; Donelan, 1990) for which some authors have proposed 
special roughness parameterizations. For instance, Drennan et al. (2003) reported that the turbulent roughness length is a function of the inverse age and significant wave height $H_{S}$ in young seas according to

$$
z_{\mathrm{r}}=3.35 H_{s}\left(\frac{u_{*}}{c_{p}}\right)^{3.4}
$$

which indicates that the roughness evolves with the wave field instead of taking a static value based on $U_{10}$. In a typical estuary or shallow embayment with shoals and a relatively deep channel, one might expect a heterogeneous spatial distribution of $z_{\mathrm{r}}$ given its dependence on $c_{p}$ and $H_{s}$, which are sensitive to topography (Holthuijsen, 2010). Moreover, salient bathymetric features such as sills and ridges may cause highly localized reductions in phase speed and wave height, which would add to the inherent complexity of the wave age field.

The concept of wave age has also been suitable in modeling the air-sea energy transfer that leads to wind wave generation and growth. The wind input, or $S_{\text {in }}$ in the parlance of Komen et al. (1984), is the source term in the wave action balance that represents the energy transfer from the wind to the wave field. Measurements and theoretical analyses (Cavaleri \& Malanotte-Rizzoli, 1981; Komen et al., 1984; Snyder et al., 1981) show that $S_{\text {in }}=A+B \cdot E$ where $A$ and $B$ are linear and exponential growth coefficients and $E$ is the wave energy spectrum as a function of frequency and direction. The exponential growth term $B$ quickly dominates over the linear and is a function of the inverse age and frequency $\sigma$ (Holthuijsen, 2010; Komen et al., 1984):

$$
B=\max \left[0,0.25 \frac{\rho_{\mathrm{a}}}{\rho}\left(28 \frac{u_{*}}{c_{p}} \cos \left(\theta-\theta_{w}\right)-1\right)\right] \sigma,
$$

where $\rho$ is the water density, and $\theta, \theta_{w}$ are the wave and wind direction, respectively. According to (3), the net energy input to the wave field is proportional to wave frequency, inverse age, and also wave height since $E \sim H_{s}^{2}$. The dependencies of the wind input to these variables also suggest that wave growth in bays and estuaries may be sensitive to topography and wind-wave misalignment caused by refraction.

In addition to modulating surface drag and wave growth, wave breaking releases energy that enhances turbulence in the surface layer (Craig \& Banner, 1994). This process is particularly important in estuaries where wall-layer theory predictions can underestimate observed dissipation rates of turbulent kinetic energy under wind waves. For example, Jones and Monismith (2008) observed that about $90 \%$ of the turbulent kinetic energy injected to the water column was provided by wave whitecapping in San Francisco Bay. An important effect of turbulence injection is a reduction in vertical shear and surface velocities (Carniel et al., 2009).

\subsection{Bottom Layer}

In the bottom boundary layer, the effective drag is modulated by waves, currents, or both. If wave and current velocities are not negligible near the bed, the effective bed roughness can be larger than that determined by physical elements such as sediment and ripples (Grant \& Madsen, 1982; Scully et al., 2018; Styles \& Glenn, 2002). In collinear wave-current flow, the maximum bed stress $\tau_{b \text {, max }}$ is the sum of the current stress $\left(\tau_{\mathrm{c}}\right)$ and the maximum wave-induced stress $\left(\tau_{w}\right)$. In this case, the vertical eddy viscosity scales with $\sqrt{\tau_{b, \max } / \rho}$ in the wave-current boundary layer and with $\sqrt{\tau_{\mathrm{c}} / \rho}$ in the current boundary layer (Styles \& Glenn, 2000). The main effect of waves in the bottom layer is then an increase in turbulence production and bed drag and a reduction in the near-bed velocity and transport. This was the case, for example, in San Francisco Bay where the inclusion of a wave-current interaction scheme led to a $10 \%$ reduction in the shallow water, root-mean-squared current speeds (Bricker et al., 2004). A similar case was modeled in Massachusetts Bay where wave-induced bed drag reduced alongshore transport by 10-50\% (Signell \& List, 1997).

\subsection{Wave-Induced Forces in the Water Column: The Vortex Force Formalism}

In terms of forces outside boundary layers, initial formulations for the wave-induced momentum flux refer to a formalism based on the radiation stress gradient (Mellor, 2010). This approach is grounded on a seminal paper by Longuet-Higgins and Stewart (1964) in which the phase-averaged vertical integrals of hydrostatic and wave-induced pressures are considered in the momentum budget (Kumar et al., 2011). Spatial 

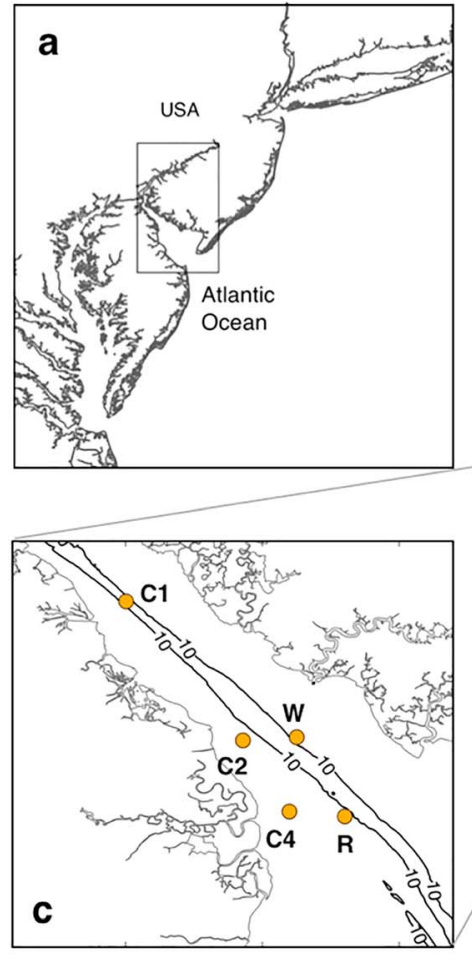

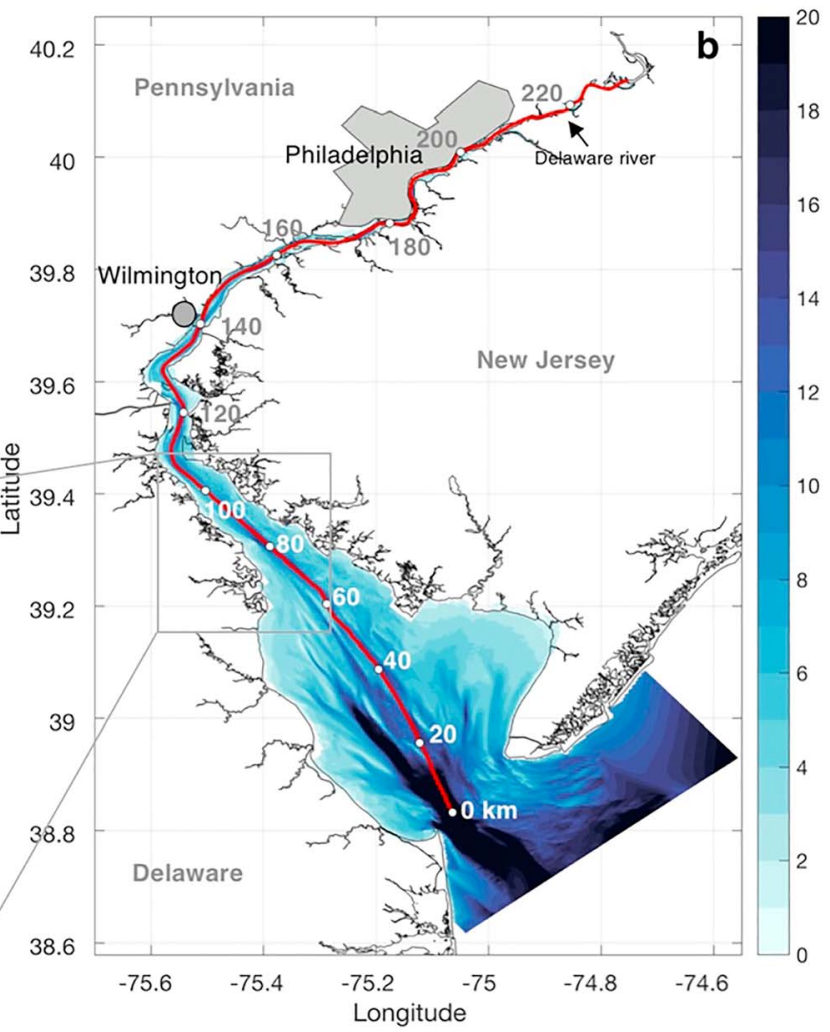

Figure 1. Delaware Bay. (a) Location on the east coast of the United States, (b) topography with color-coded depth (meters) and along-thalweg distance from the mouth of the bay to the head of the tides, (c) mooring locations $\mathrm{C} 1, \mathrm{C} 2$, C4, NOAA waverider buoy R, and wind station W at Ship John Shoal (NOAA \#853712). The 10-m isobath is shown in (c). NOAA = National Oceanic and Atmospheric Administration.

differences in horizontal momentum fluxes (e.g., due to wave breaking) lead to local changes in elevation known as wave setups and set downs (Dean \& Dalrymple, 2001). An alternative method to compute the effect of waves on 3-D currents is the vortex force formalism, which can be derived by using a Helmholtz decomposition of the advective acceleration in the Navier-Stokes equations (Uchiyama et al., 2010). A convenient feature of the vortex approach is that it cleanly separates conservative wave forces (the gradient of the Bernoulli head, the vortex force, and the Stokes-Coriolis force) from nonconservative wave forces (the acceleration induced by wave breaking). Vortex forces arise from the interaction between the current shear and the Stokes drift (Craik \& Leibovich, 1976; Nepf \& Monismith, 1991), while StokesCoriolis forces result from the effects of the Earth's rotation on the Stokes velocity. The nonconservative force corresponds to the highly turbulent momentum transfer that occurs during wave breaking. The vortex force formalism has been successfully applied in numerical models of coastal wave-current interaction. For example, the breaking-induced acceleration was a leading order momentum balance term in the inlet of Willapa Bay (Olabarrieta et al., 2014), while both breaking and vortex forces were important in a sandy beach in North Carolina (Uchiyama et al., 2010). The same approach was employed in a circulation model of a coral reef where the breaking acceleration was the same order of magnitude as the pressure gradient force and the vertical stress divergence (Rogers et al., 2017).

\subsection{Study Goals and Approach}

The main goal of this study is to evaluate how the inclusion of wind generated waves impacts the momentum budget and subtidal exchange of a realistic coastal plain estuary with complex topography. The example here is Delaware Bay, which features a dredged channel, subtidal flats, and shallow, linear ridges (Figure 1). We use a numerical model to characterize (i) the role of wave dissipation mechanisms on wave-induced forces, (ii) the impact of wind waves on surface and bed stresses over shallow, complex topography, and (iii) the contribution of wave-induced forces to the momentum budget and subtidal exchange in the bay. 

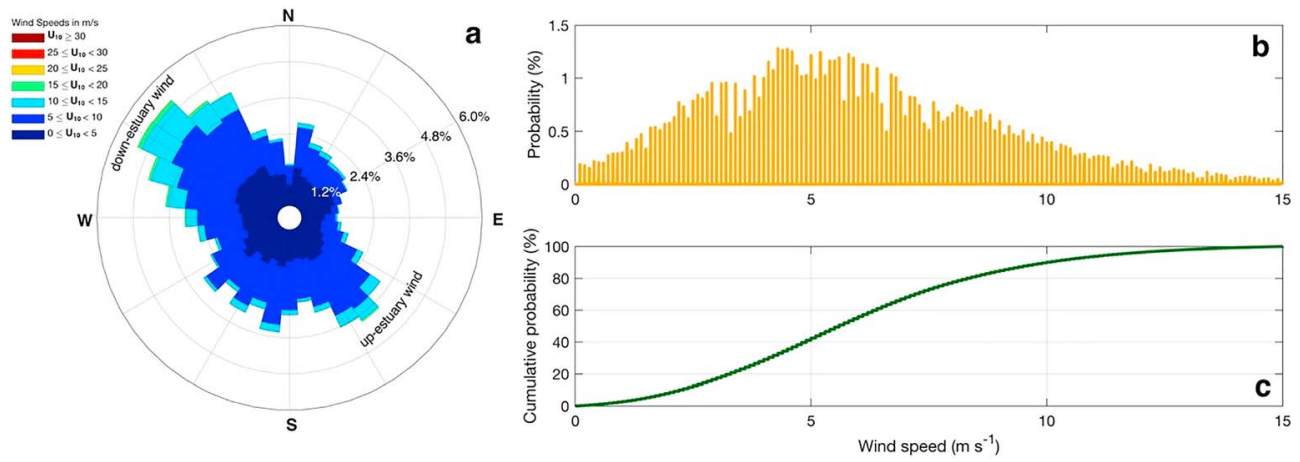

Figure 2. Wind statistics in Delaware Bay based on observations at Ship John Shoal (NOAA \#853712, station W in Figure 1) from January 2006 to November 2015. (a) Wind rose with magnitude at $10 \mathrm{~m}$ above the surface $\left(U_{10}\right)$ and direction distribution, (b) probability density function, and (c) cumulative probability. Wind rose highlights the predominance of down-estuary and up-estuary wind direction during the observation period.

One of the salient bathymetric features of the study region is its shipping channel, which has been dredged for over a century to ensure navigability into the Wilmington-Philadelphia port complex (DiLorenzo et al., 1993). Results herein allow comparison of wave dynamics with other coastal systems where wave-current interactions have been studied more thoroughly such as tidal inlets, inner continental shelves, beaches, and coral reefs.

This paper is organized as follows: Section 2 describes the main features of Delaware Bay and its wind-wave climate. We include observations of winds, waves, and tidal currents to illustrate the evolution of typical storms conditions in the estuary. Section 3 outlines the governing equations of a numerical model that computes the effect of waves on currents. Section 4 presents the model results and a discussion. Model results include a series of idealized simulations in a long channel with sloping bathymetry to assess the effect of waves on currents, as well as simulations with the realistic Delaware bathymetry and idealized forcing. Section 5 contains a summary and conclusions.

\section{Study Region: Delaware Bay}

Delaware Bay is a convergent, coastal plain estuary located on the east coast of the United States (Figure 1). The bay features a shipping channel ( $>10 \mathrm{~m}$ deep), complex bathymetric features, and broad subtidal flats ranging from 1 to $8 \mathrm{~m}$ deep. The main channel has been deepened since the early 1900s to accommodate large vessels into the Wilmington-Philadelphia port complex. Semidiurnal (M2) tides ( 1-m/s speed in the main channel) dominate the current regime in the bay. The main freshwater sources are the Delaware River with an annual mean discharge of $330 \mathrm{~m}^{3} / \mathrm{s}$ at Trenton, New Jersey, followed by the Schuylkill and Brandywine-Christine rivers (77 and $19 \mathrm{~m}^{3} / \mathrm{s}$, respectively; Sommerfield \& Wong, 2011).

Wind data from Ship John Shoal (National Oceanic and Atmospheric Administration (NOAA) station \# 853712, marked as W in Figure 1) between January 2006 and November 2015 indicate that the average wind speed is in the order of $6 \mathrm{~m} / \mathrm{s}$ and that the dominant wind directions are aligned with the main axis of the bay (Figure 2a). The strongest winds usually come from the northwest (down-estuary) and may exceed $12 \mathrm{~m} / \mathrm{s}$, although there is an important contribution of southeasterly (up-estuary) winds to the wind rose. A probability density function (Figure $2 \mathrm{~b}$ ) indicates that the most frequent speeds in the bay are in the 4- to $6-\mathrm{m} / \mathrm{s}$ range. Storms and weather events whose speed exceeds $10 \mathrm{~m} / \mathrm{s}$ were observed $10 \%$ of the time (Figure $2 \mathrm{c}$ ). Mean wind speeds are maximum during winter months $(\sim 8 \mathrm{~m} / \mathrm{s})$ and minimum during summer $(\sim 5 \mathrm{~m} / \mathrm{s})$ according to a detailed study of wind climate in the bay and adjacent continental shelf (Hughes \& Veron, 2015). Remote winds along the continental shelf also increase or decrease subtidal elevation in the bay depending on the direction of the resulting Ekman transport as demonstrated by Wong and Garvine (1984).

In addition to a focus on wind forcing, a number of authors studied wave dynamics in the bay from multiple perspectives that include the role of waves on mesoscale beach behavior (Jackson, 1995), air-sea interactions under light winds (Savtchenko et al., 1999), water level and velocities in marsh channels (Dzwonkowski 

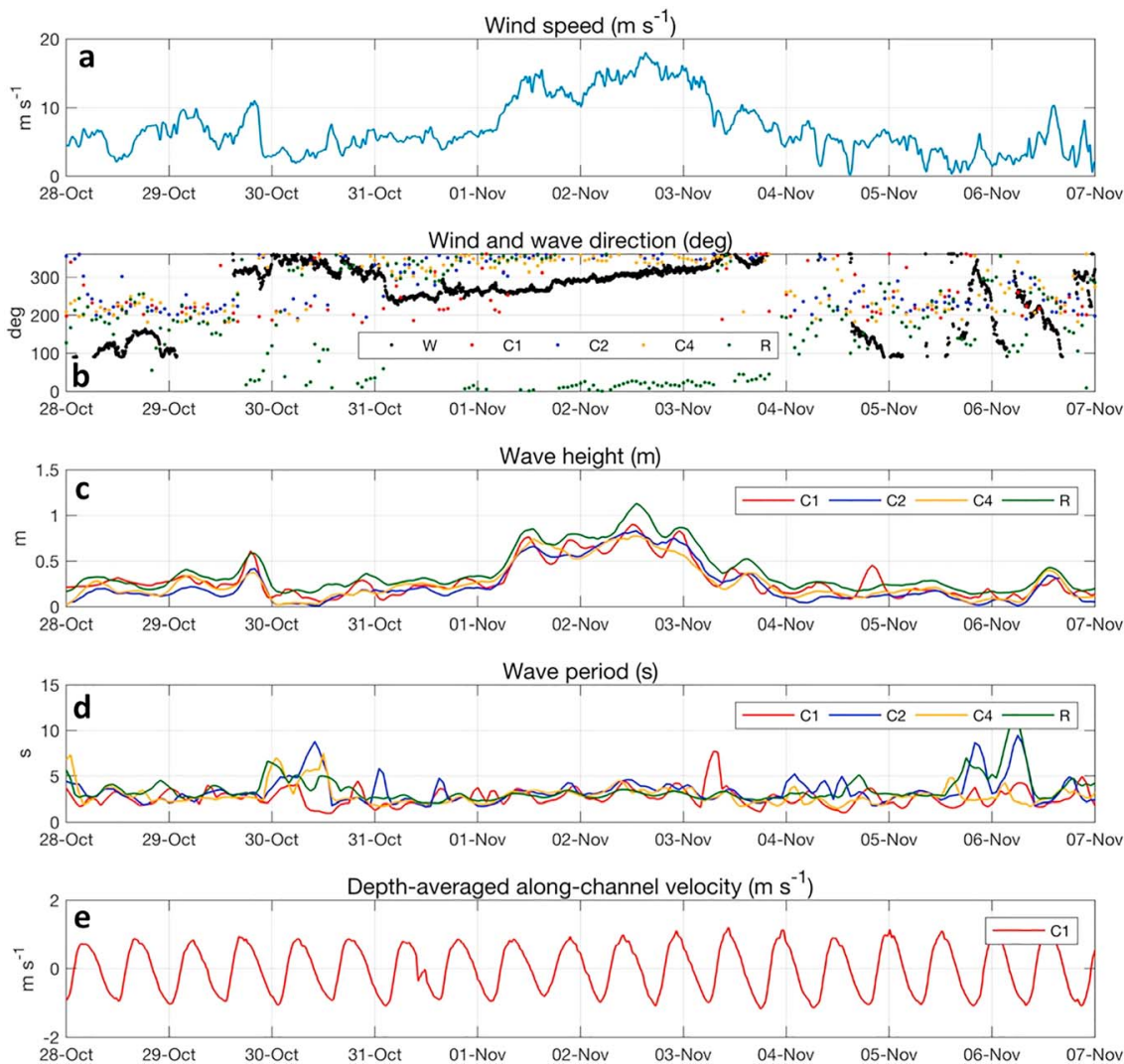

Figure 3. Observations of wind, waves, and currents in Delaware Bay during a fall storm from 28 October 2014 to 7 November 2014. (a) Wind speed from Ship John Shoal station W, (b) wind and mean wave direction, (c) significant wave height, (d) peak wave period, and (e) depth-averaged along-channel current velocity in the navigational channel (positive velocity denotes flood). Station locations are the same as in Figure 1.

et al., 2014), surface wave modeling (Jenkins, 2015), and Hurricane Sandy impacts on salt marshes of New Jersey (Elsey-Quirk, 2016). One of the main consequences of the bay's geometric and bathymetric configuration is a restriction on the up-estuary propagation of Atlantic swell. Kukulka et al. (2017) used a wave ray analysis to demonstrate that bathymetric refraction plays a key role in sheltering the lower bay from swell and that current-induced refraction at the mouth is complicated by the spatial heterogeneity of tidal currents. The study concluded that remotely generated waves cannot deeply propagate into the bay and therefore that waves are predominantly generated by local wind. The latter is in agreement with findings by Chen et al. (2018) who concluded that local winds constitute the main source of wave energy in much of the bay. However, these studies did not evaluate the role of waves in the momentum budget, surface stresses, and subtidal exchange.

For insight into the evolution of waves and currents during storm events, we deployed instruments at locations C1 (AWAC 1,000 kHz), C2, and C4 (RDI ADCP 1,200 kHz) during fall 2014 (Figure 1c). Hourly measurements of wind speed and direction were extracted from the Ship John Shoal lighthouse (W), and additional wave data were obtained from a NOAA waverider buoy (location R). A summary of wind, wave, and current observations during a down-estuary wind event from 28 October to 7 November is shown in Figure 3. Peak storm winds on 2 November reached $15 \mathrm{~m} / \mathrm{s}$ at Ship John Shoal and generated waves (0.51.0-m height, 3- 5-s period) in locations $\mathrm{C} 1, \mathrm{C} 2, \mathrm{C} 4$, and $\mathrm{R}$. The maximum wave height ( $1.2 \mathrm{~m}$ ) was registered at location $\mathrm{R}$ and was slightly greater than the measured waves in the other stations, possibly due to a longer fetch. Wave height records between 1 and 3 November suggest that tidal currents weakly modulated wave amplitude by up to $25 \mathrm{~cm}$. These observations reveal that the tidal variability of wave height and period in the bay is small relative to their mean value during the storm, which is in agreement with results presented by Kukulka et al. (2017) who also found weak interactions waves and tides in the bay through numerical modeling. 


\section{Modeling Framework}

\subsection{Coupled Modeling System}

In this study we use the Coupled Ocean Atmosphere Wave Sediment Transport (COAWST) Modeling System (Warner et al., 2010). COAWST couples a terrain-following hydrodynamic model, the Regional Ocean Modeling System (ROMS; Shchepetkin \& McWilliams, 2005) with a spectral wave model, Simulating Waves Nearshore (SWAN; Booij et al., 1999). SWAN (v41.20) calculates the wave action density (Holthuijsen, 2007):

$$
\frac{\partial N}{\partial t}+\frac{\partial\left(\vec{u}+\overrightarrow{c_{g}}\right) N}{\partial x^{\alpha}}+\frac{\partial\left(c_{\theta} N\right)}{\partial \theta}+\frac{\partial\left(c_{\sigma} N\right)}{\partial \sigma}=S,
$$

where $N$ is the wave action or energy per unit frequency, $\vec{u}$ is the surface current vector, $\overrightarrow{c_{g}}$ is the wave group velocity, $x^{\alpha}$ denotes $2-\mathrm{D}$ spatial coordinates, $c_{\ominus}$ is the refraction velocity, and $c_{\sigma}$ is the frequency shift velocity. The source term $S$ includes wind generation $S_{\mathrm{in}}$, dissipation due to whitecapping (i.e., deep water breaking) $S_{\mathrm{wc}}$, bottom friction $S_{\mathrm{bf}}$, depth-limited breaking $S_{\mathrm{br}}$, and two nonlinear redistribution processes ( $\operatorname{triad} S_{\mathrm{nl}}$ and quadruplet $S_{\mathrm{n} 14}$ wave-wave interactions). A full expression of the source term is then

$$
S=S_{\mathrm{in}}+S_{\mathrm{wc}}+S_{\mathrm{bf}}+S_{\mathrm{br}}+S_{\mathrm{nl} 3}+S_{\mathrm{nl} 4}
$$

The energy transfer from the wind to the wave field is calculated following Cavaleri and Malanotte-Rizzoli (1981) and Komen et al. (1984). Energy dissipation by whitecapping, bottom friction, and depth-limited breaking is computed with the parameterizations by Komen et al. (1984), Madsen et al. (1988), and Battjes and Janssen (1978), respectively. Within the COAWST framework, ROMS incorporates output data from SWAN and employs a vortex force formalism to compute the wave effects on currents as implemented by Kumar et al. (2012). The Navier-Stokes equation with phase-averaged wave-induced momentum terms can be written in compact form as (boldface denotes vector quantities):

$$
\frac{\partial \boldsymbol{u}}{\partial t}+\left(\boldsymbol{u} \cdot \nabla_{\perp}\right) \boldsymbol{u}+w \frac{\partial \boldsymbol{u}}{\partial z}+f \widehat{\boldsymbol{z}} \times \boldsymbol{u}+\nabla_{\perp} \varphi-\boldsymbol{F}-\boldsymbol{D}+\frac{\partial}{\partial z}\left(\overline{\boldsymbol{u}^{\prime} w^{\prime}}-v \frac{\partial \boldsymbol{u}}{\partial z}\right)=-\nabla_{\perp} K+\boldsymbol{J}+\boldsymbol{F}_{\boldsymbol{w}}
$$

where $\boldsymbol{u}=u, v ; w$ are the horizontal and vertical components of the Eulerian velocity, $z$ is the vertical coordinate, $f$ is the Coriolis factor, $\varphi$ is the normalized dynamic pressure, $\boldsymbol{F}$ is the nonwave nonconservative force, $\boldsymbol{D}$ is the diffusive term, $\overline{\boldsymbol{u}^{\prime} w^{\prime}}$ is the Reynolds stress, $v$ is the kinematic viscosity, $K$ is the Bernoulli head or the wave kinetic energy density (McWilliams et al., 2004), $\boldsymbol{J}$ is the vortex force, and $\boldsymbol{F}_{\boldsymbol{w}}$ is the nonconservative wave force. The gradient term $\nabla_{\perp} \varphi$ contains the nonwave barotropic and baroclinic pressure gradients, and the gradient of the quasi-static sea level $(\zeta)$. The latter includes an inverse barometric response term and a wave-averaged setup:

$$
\zeta=-\frac{P_{\mathrm{atm}}}{\rho g}-\frac{H_{\mathrm{rms}}^{2} k}{8 \sinh (2 \mathscr{H})}
$$

$P_{\text {atm }}$ is the atmospheric pressure, $H_{\mathrm{rms}}$ is the root-mean-squared wave height, $g$ is the gravitational acceleration, and $\mathscr{H}$ is the normalized vertical length. The expression for the vortex force $\boldsymbol{J}$ is

$$
J=-\widehat{\boldsymbol{z}} \times \boldsymbol{u}^{s t}\left[\left(\widehat{z} \cdot \nabla_{\perp} \times \boldsymbol{u}\right)+f\right]-w^{s t} \frac{\partial \boldsymbol{u}}{\partial z}
$$

where $\boldsymbol{u}^{\boldsymbol{s t}}=u^{s t}, v^{s t} ; w^{s t}$ are the components of the Stokes drift. The default algorithm for $\boldsymbol{F}_{\boldsymbol{w}}$ incorporates whitecapping and depth-limited breaking dissipation from SWAN and converts them into forces in ROMS according to

$$
\boldsymbol{F}_{\boldsymbol{w}}=\frac{\left(S_{\mathrm{wc}}+S_{\mathrm{br}}\right)}{\rho \sigma} f^{b}(z) \boldsymbol{k},
$$

in which $f^{b}(z)$ is a surface-enhanced vertical distribution function, and $\boldsymbol{k}$ is the wavenumber vector. Regarding the conservation of mass, the total water transport depends on the Lagrangian velocity field $\boldsymbol{u}^{\boldsymbol{l}}$ given by the sum of the Eulerian and wave-induced Stokes velocities:

$$
u^{l}=u+u^{s t}
$$




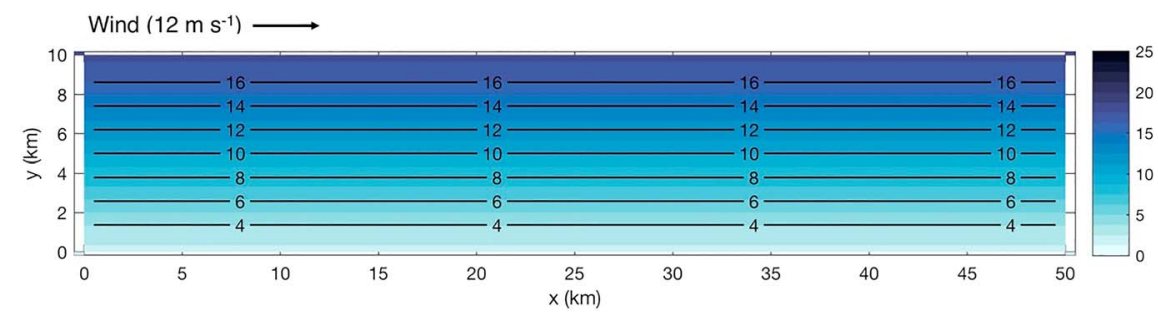

Figure 4. Idealized model basin with linearly sloping bottom. Depth units are in meters (colors and contours).

For details on the implementation of equations (6)-(10) in ROMS, the reader is referred to Kumar et al. (2012, sections 2 and 3). We will refer to the 2-D (depth- and tidally averaged) momentum terms as

$$
\mathrm{ACC}+\mathrm{HADV}=\mathrm{PGF}+\mathrm{COR}+\mathrm{SSTR}+\mathrm{BSTR}+\mathrm{HJVF}+\mathrm{StkCOR}+\mathrm{BRK}
$$

where each term denotes, respectively, the magnitude of the local acceleration, horizontal advection, the forces associated to pressure gradients, Coriolis, surface stress, bottom stress, the horizontal vortex force, the Stokes-Coriolis force, and the breaking force. Equation (11) neglects the horizontal mixing term, while PGF contains the contributions of both $\nabla_{\perp} \varphi$ and $\nabla_{\perp} K$ (see equation (6)).

\subsection{Idealized Simulations and Model Evaluation}

Prior to running the model with realistic bathymetry, we prepared a series of runs in an idealized basin with linearly sloping bottom and depth values similar to Delaware Bay $(2-18 \mathrm{~m})$. The goal of this preliminary assessment is to examine the differences in the wind-driven momentum budget with and without waves under the default implementation of the vortex force formalism presented in Kumar et al. (2012). Results will then be used to inform the more computationally expensive simulations in the bay. The setup consists of a closed basin forced with axial, constant wind $(12 \mathrm{~m} / \mathrm{s})$ until steady state. The depth distribution $h(x, y)$ is similar to that used in Signell et al. (1990):

$$
h(x, y)=H_{\max }-\left(H_{\max }-H_{\min }\right)\left(\frac{W-y}{W}\right),
$$

where the depth limits are $H_{\max }=18 \mathrm{~m}, H_{\min }=2 \mathrm{~m}, W=10 \mathrm{~km}$ is the basin width, and $x, y$ are the along and across-basin coordinates. The horizontal domain has $50 \times 30$ grid points, and the length of the channel is $L_{b}=50 \mathrm{~km}$ (Figure 4).

The first idealized simulation is conducted with ROMS without wave coupling and is referred to as "uncoupled." The wind stress is calculated according to the COARE 3.0 formulation (Fairall et al., 2003), bottom friction is computed based on a log profile with a roughness length of $1 \mathrm{~mm}$, and turbulent mixing is parameterized according to the $k-\varepsilon$ closure scheme (Warner et al., 2005). The second run is a "coupled" ROMS and SWAN (COAWST) simulation in which waves are generated by the same axial winds. The effect of waves on currents is considered by activating both the vortex force formalism and the Signell-SherwoodWarner (SSW_BBL) scheme for bottom boundary layer flows (Warner et al., 2008). Both setups are run until a steady wind-driven circulation is obtained. Results for the wave height, period, surface currents, alongchannel transport, and momentum balance terms are presented in Figure 5.

For the coupled run, $H_{s}$ and $T_{p}$ are, respectively, between $0.7-1.0 \mathrm{~m}$ and $2.5-4.25 \mathrm{~s}$ with values increasing with depth (Figure 5a). The effect of wave coupling on surface currents is shown in Figure 5b. For the uncoupled case, the maximum downwind (i.e., positive) surface current was approximately $0.35 \mathrm{~m} / \mathrm{s}$ and increased by $29 \%(0.45 \mathrm{~m} / \mathrm{s})$ when waves were included. Note that the plotted surface velocity for the coupled case considers both the Eulerian and Stokes components. The surface Stokes velocity was $\sim 0.1 \mathrm{~m} / \mathrm{s}$ across the basin (roughly $1 \%$ of the wind speed) consistent with wind-generated waves propagating in the downwind direction. Regarding the momentum balance, the downwind SSTR opposes the upwind PGF for both modeled scenarios. However, note that the PGF in the coupled case is 1.25 times higher than the uncoupled PGF. By examining the coupled downwind momentum terms, the increase in PGF is likely due to the BRK term whose net effect is to contribute to the SSTR. The interplay of SSTR, PGF, and BRK over the sloping bottom 

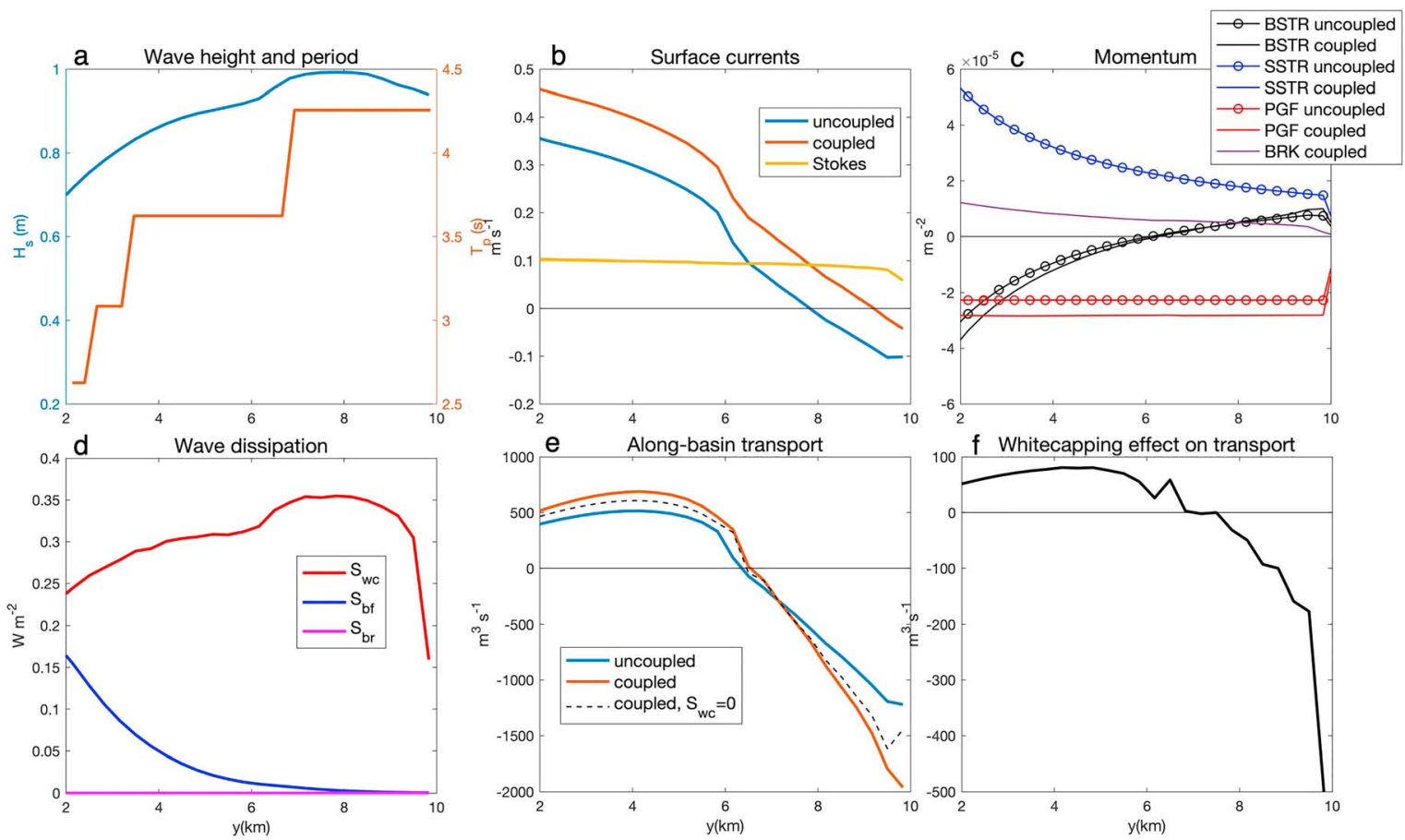

Figure 5. Idealized model results. (a) Wave height and period for the coupled case, (b) surface currents including the Stokes drift, (c) leading-order steady momentum balance terms: bottom stress, surface stress, pressure gradient force, and breaking force (BSTR, SSTR, PGF, and BRK, respectively), (d) wave dissipation terms in the coupled run, (e) along-basin transport at each grid point, and (f) effect of whitecapping on transport when included in the breaking force scheme. All results are shown as a function of cross-channel distance in the middle of the basin. Positive values for the momentum and transport terms denote downwind direction.

generates a laterally sheared circulation with downwind depth-averaged flow in shallow water and upwind in the deeper areas, indicative of a topographically induced gyre as reported by Csanady (1973) in long lakes. The separation depth between downwind and upwind transports $(6.5 \mathrm{~m})$ is a function of the standard deviation of the cross-channel depth normalized by the mean depth (Hunter \& Hearn, 1987). For both scenarios, this sheared circulation pattern is evident in the change of sign in the BSTR term and alongbasin transport (Figure 5e). The overall momentum analysis here indicates that the BRK term may play a key role in wave-driven flows (vortex forces were about two orders of magnitude smaller than the leading terms and are not shown). According to (9), the nonconservative wave force (i.e., BRK) depends on both $S_{\mathrm{br}}$ and $S_{\mathrm{wc}}$. We show in Figure $5 \mathrm{~d}$ that $S_{\mathrm{br}}$ is zero while $S_{\mathrm{wc}}$ ranges from 0.15 to $0.35 \mathrm{~W} / \mathrm{m}^{2}$, therefore whitecapping is the only dissipation term that contributes to BRK. The impact of full wave coupling on the horizontal circulation can be assessed by calculating the steady downwind transport $(T)$ for each run (Signell et al., 1990):

$$
T=\frac{1}{2} \int_{-h(x *, y)}^{\eta} \int_{0}^{W}\left|u^{l}(y, z)\right| \mathrm{d} y \mathrm{~d} z
$$

where $\eta$ is the free surface and $x_{*}=L_{b} / 2$. Note that the uncoupled scenario considers no wave-induced Stokes velocity and thus $u^{l}$ reduces to the Eulerian $u$ in that case. Results show that $T=9.94 \cdot 10^{3} \mathrm{~m}^{3} / \mathrm{s}$ for the coupled case and $T=7.31 \cdot 10^{3} \mathrm{~m}^{3} / \mathrm{s}$ for the uncoupled, therefore the incorporation of waves increased transport by a factor of 1.36 . This discrepancy between model runs prompts a closer look at the role of waves on circulation.

Given the results of the momentum analysis, we first consider the BRK term. The notion that a waveinduced force is proportional to dissipation can be traced to a coastal engineering study by Dingemans et al. (1987), who calculated the driving force directly from dissipation instead of differentiating the radiation stress tensor. However, their model setup consisted of a mild-slope nearshore environment in which the leading dissipation terms are expected to be $S_{\mathrm{br}}$ and $S_{\mathrm{bf}}$ and not $S_{\mathrm{wc}}$ since waves were not generated by 
winds but prescribed at the ocean boundary. Further research on the role of wave energy dissipation on circulation continued over three decades (see, e.g., Ardhuin et al., 2004; Perrie et al., 2003; and more recently Aiki \& Greatbatch, 2014), but there is some consensus, albeit preliminary, that whitecapping is integrally equivalent to the wind stress under wind-wave equilibrium (Sullivan et al., 2007; Uchiyama et al., 2010). In the light of this evidence, we surmise that including whitecapping as a vertically distributed body force in the budget is unsuitable because the contribution is already included in the wind stress. Therefore, we modify the coupling in ROMS to retain $S_{\mathrm{br}}$ as the only contributor for the nonconservative wave force (i.e., we propose to set $S_{\mathrm{wc}}=0$ in equation (9)). This modification has no impact on wave-induced surface mixing and drag and is consistent with additional options within the COAWST framework in which the breaking force is computed only based on $S_{\text {br }}$ according to formulas by Thornton and Guza (1983) or Church and Thornton (1993) without incorporating wave dissipation from SWAN. For the coupled case considered here, removal of whitecapping led to an adjusted $T=8.86 \cdot 10^{3} \mathrm{~m}^{3} / \mathrm{s}$, and thus the excess waveinduced transport decreased from $36 \%$ to $21 \%$. The cross-channel distribution of the whitecapping-induced transport is shown in Figure 5f. The remaining 21\% increase in $T$ with respect to the uncoupled case is then approximately due to the Stokes drift. We consider that this adjustment to the model is appropriate in general for future applications with wind-generated waves.

\subsection{Numerical Experiments With Realistic Bathymetry}

After removing whitecapping from the breaking force, we proceeded with the realistic Delaware Bay runs. We prepared four realistic model configurations to study the role of waves on drag, momentum budget, and circulation in the bay. All model setups use a structured curvilinear grid (20 vertical levels and 1,276 by 184 horizontal points with spatial resolution ranging from $440 \mathrm{~m}$ at the mouth to $6 \mathrm{~m}$ in the river) and bathymetry from a composite of recent soundings by NOAA and the U.S. Army Corps of Engineers (last updated 2014, depth distributions shown in Figure 1). The oceanic open boundary is located on the inner continental shelf, while the northern edge of the domain corresponds to the head of the tides ( $\mathrm{km} 220$ in Figure 1b).

\subsubsection{ROMS Benchmark Runs}

The goal of the benchmark runs is to explore the role of winds in the momentum balance and subtidal exchange of the bay without waves. Two cases are considered here, one with up-estuary and another with down-estuary winds according to the wind rose in Figure $2 \mathrm{a}\left(13 \mathrm{~m} / \mathrm{s}\right.$ with directions $124^{\circ}$ and $304^{\circ}$, respectively). Tidal forcing (M2 constituent) is obtained from the ADCIRC database (Luettich et al., 1992). The surface stress is calculated according to the COARE 3.0 algorithm in which the surface drag coefficient is a function of wind speed (Fairall et al., 2003).

\subsubsection{Coupled ROMS and SWAN (COAWST) Runs}

The coupled runs employ the same parameters and forcing as the benchmark (M2 tides, $124^{\circ}$ and $304^{\circ}$ winds) and incorporate a previously validated SWAN configuration of the bay to compute the effect of waves on currents and drag (Chen et al., 2018). The coupled model has several options to consider waves on air-sea drag. The steepness-based parameterization of Taylor and Yelland (2001) was found to perform well with many data sets except in short-fetch and young sea conditions (Drennan et al., 2005). Since the Delaware wave field has fetch-limited shadow zones, we considered that option unsuitable. The wave age-based parameterization from Oost et al. (2002) was found to overpredict surface currents under hurricane winds (Olabarrieta et al., 2012). In this study, we used Drennan's parameterization (2), which had a good performance in wind-sea rough flows (Drennan et al., 2003, 2005). The bottom friction algorithm (SSW_BBL) includes wave-current interactions (Warner et al., 2008), and the wave-induced forces are computed with the vortex force formalism without whitecapping. Surface mixing accounts for wave breaking according to Craig and Banner (1994) as implemented by Carniel et al. (2009). Since previous studies have shown that the bay is sheltered from remote swell (Chen et al., 2018; Kukulka et al., 2017), we neglect wave forcing at the open boundary.

To perform the runs with a realistic spatial density distribution, a climatological salinity field (Levin et al., $2018)$ is ramped up under median river discharge in the Delaware River $\left(350 \mathrm{~m}^{3} / \mathrm{s}\right)$ for 60 tidal cycles. The evolved salt field is then used as initial condition for the runs we analyze here. Wind forcing (with wave generation for the coupled runs) is then prescribed for 5 days, consistent with previous studies of wind-driven circulation in a similar coastal environment (Whitney \& Codiga, 2011). We use input parameters and 
Table 1

Summary of Model Configurations

\begin{tabular}{cccccccc}
\hline Run & ROMS & SWAN & Wind stress & Bottom stress & Wave forces & Wind direction & Runtime \\
\hline 1 & $\checkmark$ & $\times$ & COARE 3.0 & Log profile & $\times$ & $124^{\circ}$ & 5 days \\
2 & $\checkmark$ & $\times$ & & & $\times$ & $304^{\circ}$ & \\
3 & $\checkmark$ & $\checkmark$ & Drennan et al. (2003) & Warner et al. (2008), & $\checkmark$ & $124^{\circ}$ & \\
4 & $\checkmark$ & $\checkmark$ & & SSW_BBL & $\checkmark$ & $304^{\circ}$ & \\
\hline
\end{tabular}

Note. ROMS = Regional Ocean Modeling System; SWAN = Simulating Waves Nearshore; COARE = Coupled Ocean Atmosphere Response Experiment.

advection schemes from a previously validated model setup of the bay (Chen et al., 2018), and further details can be found there. A summary of the model setups is presented in Table 1.

\section{Results and Discussion}

In this section, we will analyze model output to investigate the role of wind waves in drag and momentum budget of Delaware Bay. Our focus in this part of the analysis is to illustrate how waves change the magnitude of drag and momentum budget terms; therefore, we will consider the up-estuary wind case in most of the discussion for brevity. We will then explore the impact of waves on the bay-ocean exchange and will consider both wind and wave directions.

\subsection{Wind Waves and Surface Stress}

The wind input for wave energy $S_{\text {in }}$ and the surface drag coefficient $C_{D}$ (equations (1)-(3)) involve dependencies on the wave age, phase speed, height, and frequency. Since the bay features a complex bathymetric and geometric configuration with channels, ridges, and a narrow river, it is important to discuss the extent of wind-wave equilibrium under typical wind conditions. To assess the wave equilibrium in the study region, Chen et al. (2018) obtained the stationary, infinite-fetch wave height for a range of depths typical of the bay and compared the results against the simulated heights in a realistic Delaware domain under up- and downestuary winds. The authors identified that fetch and steeply sloping bathymetry were the main factors that lead to local disequilibrium. In terms of fetch, the study indicates that at least $10 \mathrm{~km}$ is necessary for local wind waves to fully saturate in a water column $4 \mathrm{~m}$ deep. The latter explains the relatively small wave heights in the narrow river north of $39.5^{\circ} \mathrm{N}$ (about $0.5 \mathrm{~m}$ as shown in Figure 6a). In the lower bay, the study indicates that wave heights are in equilibrium and near-equilibrium with local wind and depth during typical storm conditions, with the exception of highly localized steep ridges where the depth profile changes more rapidly than waves can adjust. While the assessment of wave equilibrium from Chen et al. (2018) did not incorporate tidal forcing, the impact of wave-current interactions on wave height and nearequilibrium conditions is expected to be modest according to Kukulka et al. (2017), who reported that currents modulated average wave statistics by about 15\% in Delaware Bay.

In the present study, the tidally averaged significant wave height $\left(H_{s}\right)$ mirrors the broad basin topography with maximum values in the deepest regions of the lower bay $\left(H_{s} \sim 1.5 \mathrm{~m}\right.$, Figure $\left.6 \mathrm{a}\right)$ and reflects the findings by Chen et al. (2018) regarding equilibrium and disequilibrium conditions. Wave heights at shoreline edges in the lower bay were relatively small $\left(H_{S} \sim 0.25 \mathrm{~m}\right)$, which is indicative of enhanced energy dissipation through bottom friction and whitecapping as waves propagate onshore. Note that the slight reduction of wave height and period from the mouth to the oceanic boundary of the model (Figure 6a) is indicative of a fetch artificially limited by the model grid for up-estuary winds rather than a physical response. Topography also modulated the peak wave period $T_{p}$ (Figure 6b), which ranged from 3 to $4 \mathrm{~s}$ in the lower bay to $1-3 \mathrm{~s}$ in relatively shallow regions. The basin-wide median ratio of local depth to wavelength $(h /$ $L_{w}$ ) was 1.03 with a minimum 0.12 , which indicates that waves in the estuary are predominately dispersive $\left(h / L_{w}>0.5\right.$; Figure 6c), and therefore that the phase speed is mainly a function of wavelength, $c_{p} \approx \sqrt{g L_{w} / 2 \pi}$.

The topography and fetch-controlled wave height field was also reflected in the spatial structure of the $S_{\mathrm{in}}$, which ranged from $0.8 \mathrm{~W} / \mathrm{m}^{2}$ on subtidal flats and to $\sim 1.3 \mathrm{~W} / \mathrm{m}^{2}$ in the lower bay (Figure 7a). A close examination of the wind input expression can provide insight into the nature of these results. As shown in 

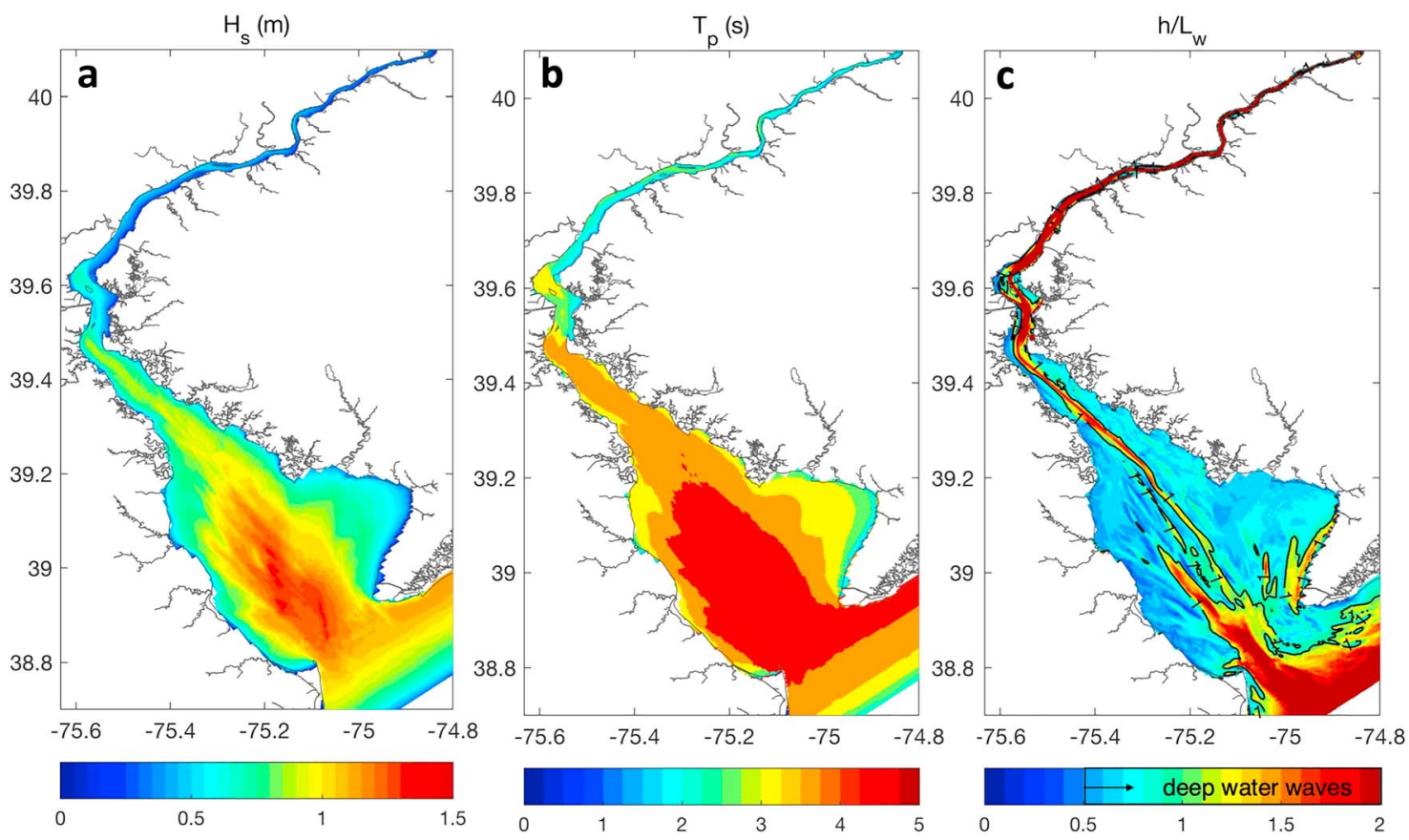

Figure 6. Modeled spatial patterns of tidally averaged (a) significant wave height, (b) peak period, and (c) ratio of water depth to wavelength from the coupled model and up-estuary winds. The black contour in (c) denotes the basin-wide median value of $h / L_{w}$, and the color bar highlights values for deep water waves.

equation (3), $S_{\text {in }}$ depends on an exponential growth term $(B)$ that is proportional to inverse age, wind and wave direction, and frequency. Model results indicate that the wind-wave direction misalignment due to topographic and current-induced refraction $\left(\theta-\theta_{w}\right.$, not shown) was about $15^{\circ}$, which modulates $B$ spatially by $5 \%$. Values of $B$ in the bay therefore decrease with increasing depth following the drop in $\sigma$ and $u_{*} / c_{p}$ as waves become older, longer, and more dispersive (Figures $7 \mathrm{~b}$ and $7 \mathrm{c}$ ). Values of the inverse age in the bay (Figure $7 \mathrm{~b}$ ) are $\sim 0.13$ in deep water and $\sim 0.2$ over subtidal flats (ages $\sim 7.7$ and $\sim 5$, respectively); therefore, the sea is underdeveloped (age $<33$, or "young"). However, $S_{\text {in }}$ is greatest in deeper water where the older, longer waves are located, suggesting that wave height is the main controlling variable in the energy transfer from winds to waves. Note that in the wind input term, $B$ is multiplied by the energy spectrum $E$, which is proportional to $H_{s}^{2}$. Simulation results then indicate that under spatially homogeneous wind speed and direction, the net wind energy transfer to the wave field in the bay depends largely on depth and fetch through their controlling effect on wave height.

While the simulation under constant wind speed and direction allows a basic analysis of the variables that control wave growth, it is relevant to note that wind direction can also change rapidly and increase windwave misalignment during certain weather events. Field observations (Figure 2) indicate that the wind-wave direction misalignment was approximately $60^{\circ}$ between 31 October and 2 November when the wind vector changed direction from $250^{\circ}$ to $300^{\circ}$. Intuitively, increasing values of misalignment would reduce $B$ through the cosine term in (3), damping wave growth. However, there are additional wave dynamics that can result from veering winds, especially in estuaries and similar environments where wind direction and coastline configuration determine fetch. For instance, a changing wind direction can increase the fetch (Donelan et al., 1985) and bring local wind seas closer to saturation. In estuaries such as Chesapeake Bay, the misalignment between wind and waves due to the basin geometry is translated into a wind stress divergence at the air-sea surface (Fisher et al., 2017).

In addition to exploring air-sea wave energy coupling, we now present results of the surface drag coefficient for modeled scenarios without and with waves. In the uncoupled scenario, $C_{D}$ was calculated according to the COARE 3.0 algorithm in which Charnock's alpha is only a function of wind speed (Figure 7d). As expected, the drag coefficient for that case was spatially homogeneous $\left(C_{D} \sim 1.6 \cdot 10^{-3}\right)$. In contrast, the coefficient in the coupled run ranged from $1.6 \cdot 10^{-3}$ in relatively shallow water to $2.3 \cdot 10^{-3}$ in the main channel 

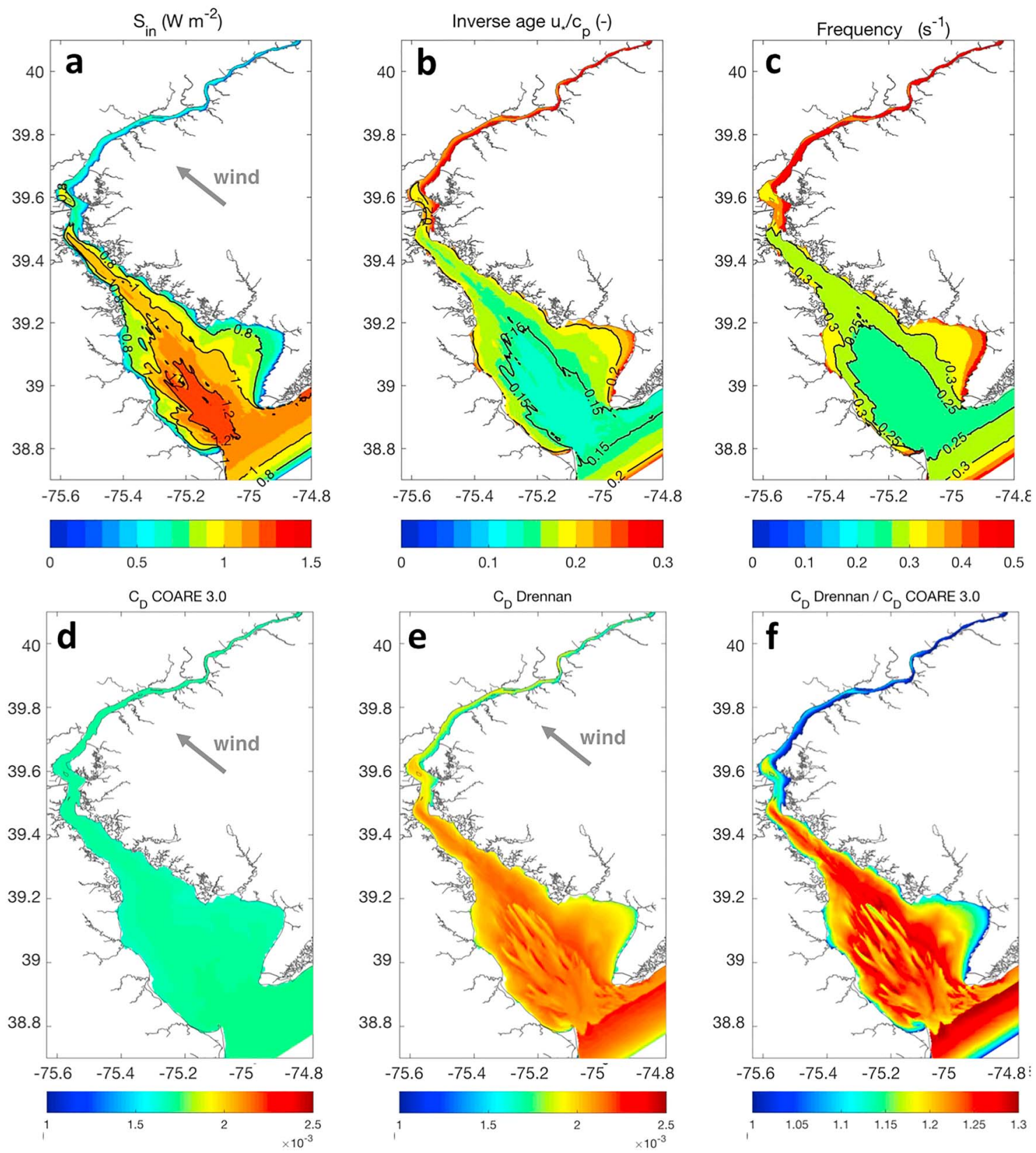

Figure 7. Air-sea wave coupling in Delaware Bay. (a) Wind input for the wave action balance, (b) inverse wave age, (c), wave frequency, surface drag coefficient according to (d) the COARE 3.0 algorithm and (e) the inverse wave age and height (Drennan) parameterization. The ratio between drag coefficients is shown in (f). COARE $=$ Coupled Ocean Atmosphere Response Experiment.

and adjacent continental shelf (Figure 7e). The spatial pattern of $C_{D}$ in the coupled scenario is complicated by the counteracting effects of wave height and age in the bay. As described in the discussion on $S_{\mathrm{in}}$, wave heights are maximum where the inverse age is minimum, which explains the slight reduction of drag toward the lower bay where the sea is relatively older. The ratio between the two drag coefficients (Figure 7f) indicates that $C_{D}$ was up to $30 \%$ higher in the coupled run. In the upper tidal river where fetch limitation and a narrow channel severely limit wave growth, the drag coefficient remained nearly unchanged with the wave coupling.

The effect of waves on surface drag in estuaries was also studied in regions where basin geometry and prevailing wind direction are more conducive to fetch-limited wave growth compared to Delaware Bay. An example is Chesapeake Bay, where Fisher et al. (2015) analyzed the impact of wave age on $C_{D}$ based on 


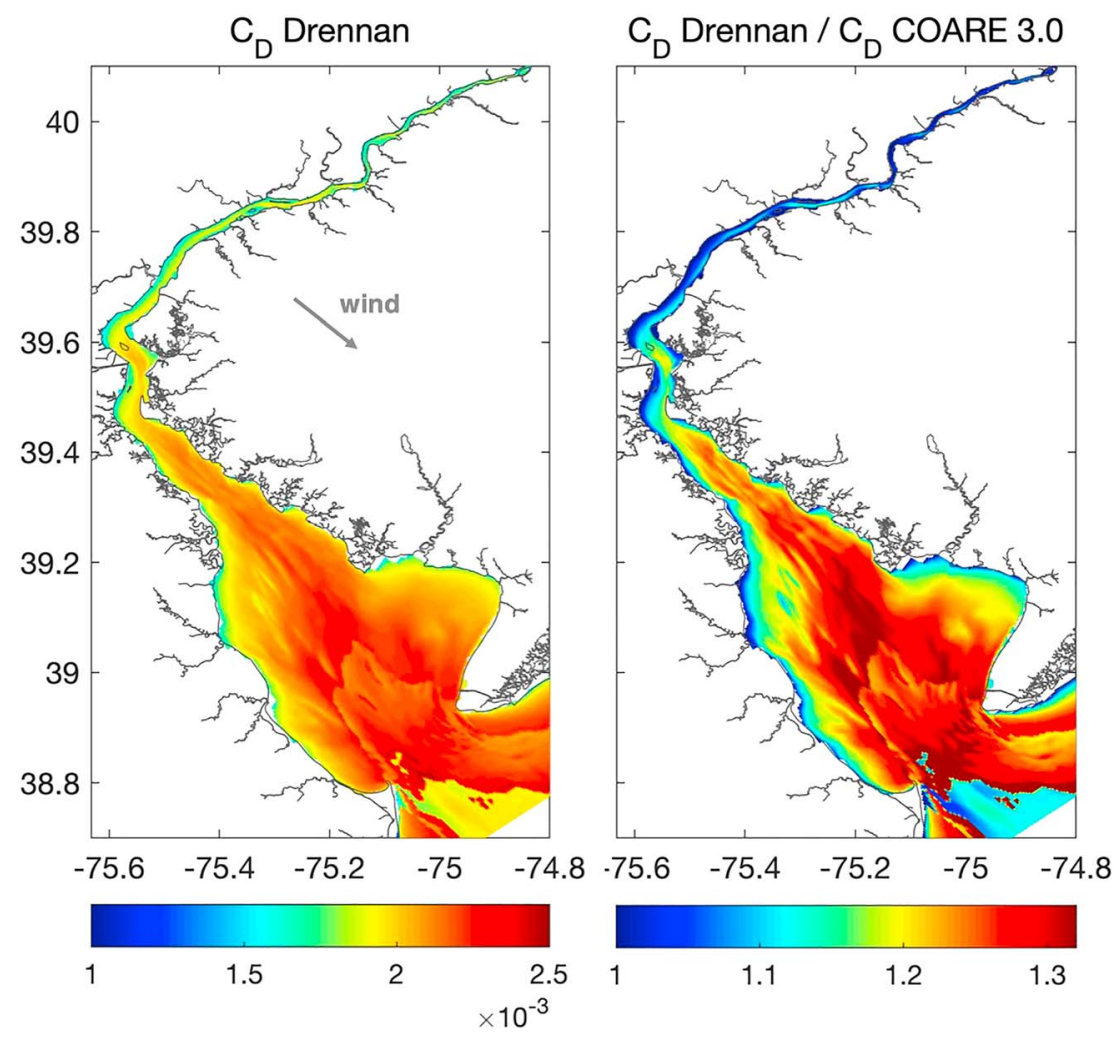

Figure 8. (left) Surface drag coefficient for down-estuary winds based on the Drennan parameterization. (right) Increment factor with respect to the COARE 3.0 formulation. COARE $=$ Coupled Ocean Atmosphere Response Experiment.

observations and numerical modeling. Their study reports that the turbulent roughness length in the Chesapeake follows the relationship $z_{r} g / u_{*}^{2}=A_{c}\left(u_{*} / c_{p}\right)^{B_{c}}$ with $A_{c}=0.137$ and $B_{c}=0.928$ as empirical constants, in contrast to deep ocean, unlimited fetch conditions where $A_{c}=0.114$ and $B_{c}=0.622$ (Edson et al., 2013). While Fisher et al's roughness parameterization does not explicitly include wave height as in Drennan's model (2), the spatial distribution of the wave-influenced $C_{D}$ was comparable to that in Delaware Bay, as it also ranged from $1-2.5 \cdot 10^{-3}$ under slightly lower wind speeds $(\sim 10 \mathrm{~m} / \mathrm{s})$. Similarly, they found departures in the wave-induced $C_{D}$ of up to $20 \%$ with respect to a drag formulation that depends only on wind speed. Other authors found that the measured drag coefficient at a nearshore tidal inlet was 2.5 times higher than the predicted open ocean bulk value under moderate $(>5 \mathrm{~m} / \mathrm{s})$ winds (Ortiz-Suslow et al., 2015). The discrepancy in the Delaware model results was less, perhaps because the model grid does not spatially resolve the surfzone. Both the observational evidence in other systems and our model results indicate that waves can play an important role in the surface drag distribution of shallow, fetch-limited environments.

Although the up-estuary wind case illustrates the typical response of $C_{D}$ to the wave field, it is important to briefly address the role of wind direction in the spatial distribution of surface drag. The modeled $C_{D}$ for the down-estuary wind-wave scenario and the increment factor with respect to the COARE 3.0 formulation are shown in Figure 8. The spatial distribution is similar to the modeled up-estuary $C_{D}$ (Figures 7e and 7f) in that the drag increases from the shorelines to the middle of the bay, with finer spatial patterns imposed by bathymetry through its control on $H_{s}$ and $u_{*} / c_{p}$. Another similarity between the two cases is the dominance of below-equilibrium conditions in the narrow river where fetch-limited waves also had a modest $(<10 \%)$ impact on drag. The main difference between the up-estuary and down-estuary wave-induced $C_{D}$ distribution is in the region between the mouth and the oceanic boundary of the model. Since the wind blows toward the open boundary in this case, the wave field is not affected by artificial fetch limitations. The slight decrease in drag from the mouth toward the shelf in this case is not due to the proximity of the model 

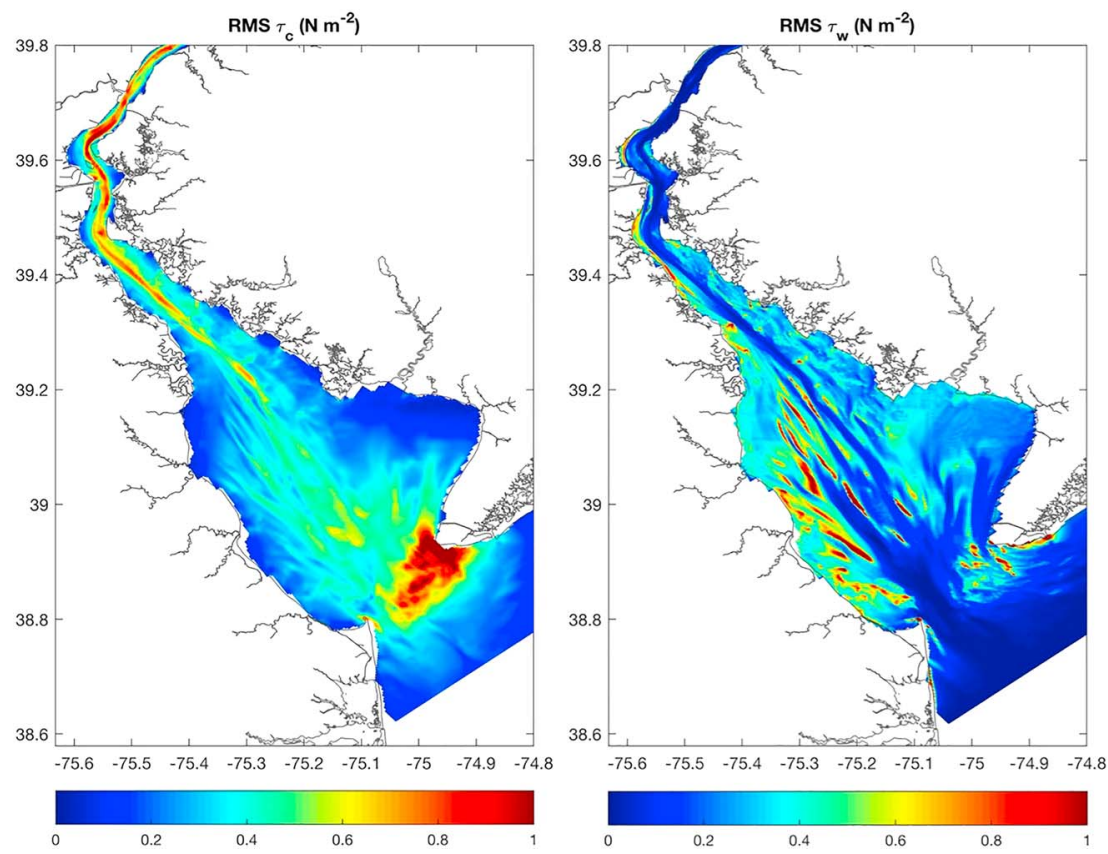

Figure 9. RMS (left) current bed stress $\tau_{\mathrm{c}}$ and (right) wave-induced bed stress $\tau_{\mathrm{w}}$ under up-estuary winds. RMS $=$ rootmean-squared.

boundary but because wind waves in the inner shelf are able to grow older than inside the bay. The seaward reduction of $C_{D}$ is this area (about $22 \%$ from midbay to the shelf) therefore suggests that wave age and not height dominates the surface roughness. While the model captures the basic roughness dynamics that would take place on the inner shelf under purely wind-driven conditions, the surface drag in a more realistic situation would be affected by swell (e.g., mixed sea conditions). In that case, swell would complicate the purely wind-sea drag by accepting or releasing momentum at the air-sea boundary as a function of wind speed (Garcia-Nava et al., 2012). However, the transition from mixed conditions to swellsheltered estuarine wind seas is beyond the scope of the present work. Later we will examine the implications of the extra wave-induced surface drag for the momentum budget and residual circulation in the bay.

\subsection{Wind Waves and Bottom Stresses}

Following the examination of air-sea wave coupling, we now consider the impact of waves in the bottom boundary layer. The spatial distribution of root-mean-squared bottom current and wave stresses is shown in Figure 9. Current stresses ( $\tau_{c}$; Figure 9, left) were relatively important in the thalweg north of $39.2^{\circ} \mathrm{N}$ $\left(\sim 1 \mathrm{~N} / \mathrm{m}^{2}\right)$, consistent with the effect of topographic funneling on tidal current amplification (Friedrichs \& Aubrey, 1994), and also in the bay's mouth due to the forced flow curvature as tides enter the bay. In the lower bay area, current stresses were $0.4-0.6 \mathrm{~N} / \mathrm{m}^{2}$ in the deeper regions and $<0.2 \mathrm{~N} / \mathrm{m}^{2}$ over shoals, which suggests that most of the momentum is conveyed in the relatively deep channel. In contrast, wave-induced stresses were only important in very shallow regions of the bay (Figure 9, right), especially over shoals and along linear ridges as reported by Chen et al. (2018) under higher wind speeds. Wave stresses on top of ridges in the lower bay $\left(\sim 1 \mathrm{~N} / \mathrm{m}^{2}\right)$ were comparable to the current stresses in relatively deeper water.

Since wave stresses were highly localized and over areas that do not convey most of the momentum, the impact of the enhanced bed drag on the overall tidally and wind-driven circulation was relatively small. A similar case was observed in San Francisco Bay where wave-current interactions in the bottom layer had a little impact on tidal propagation (Bricker, 2003). However, the spatial distribution of the wave stresses would have a direct impact in sediment resuspension and transport since the surface erosion flux is proportional to the difference between the maximum stress $\tau_{b \text {, max }}$ and the critical erosional stress for each sediment class (sand, silt, or clay) present in the bed (Warner et al., 2008). The resulting wave-driven 


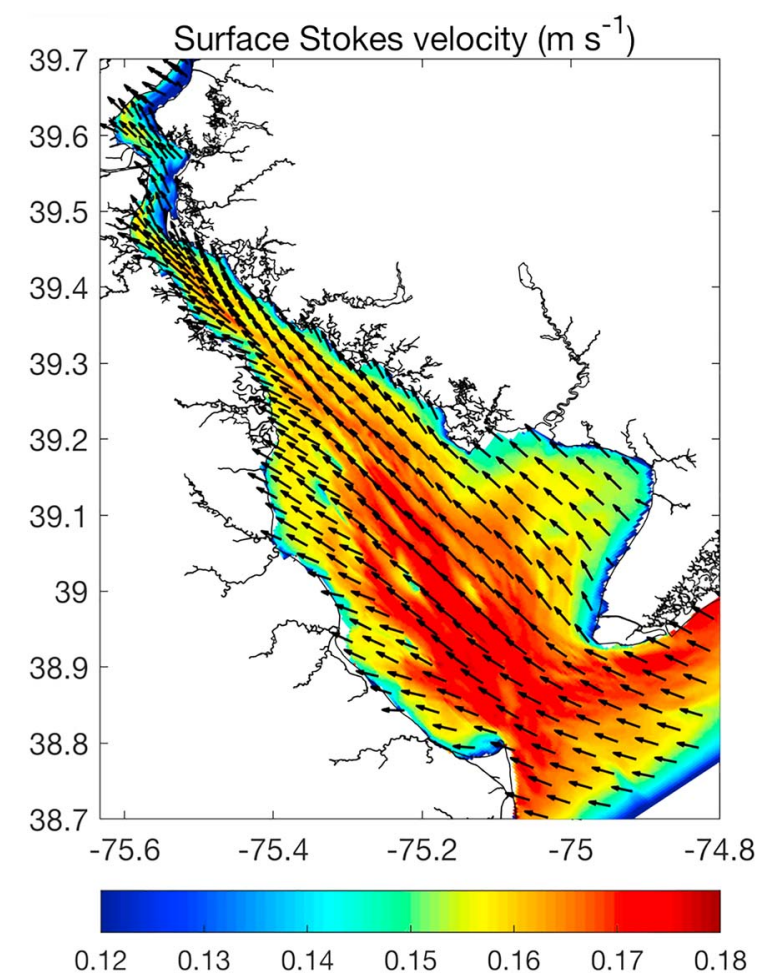

Figure 10. Tidally averaged surface Stokes velocity (arrows) with magnitude in colors $(\mathrm{m} / \mathrm{s})$ for the coupled, up-estuary wind run. sediment erosion during storms would contribute to the along- and crossbay sediment budgets of the bay, which are usually dominated by mean advection and tidal pumping (McSweeney, Chant, \& Sommerfield, 2016; Sommerfield \& Wong, 2011). In addition, enhanced water column turbidity due to waves could impact light availability and biological productivity at storm time scales (Cho, 2007; McSweeney, Chant, Wilkin, et al., 2016), but the response of bed sediment to wave forcing is outside the scope of this work.

\subsection{Water Column Momentum Budget}

In the previous two sections we analyzed the variability of surface and bottom stresses in the context of wind-generated waves. Next we explore the spatial distribution of the mean (tidally and depth-averaged) momentum budget in the coupled and uncoupled runs under up-estuary winds. One of the main features of the coupled model is the inclusion of the Stokes drift in the velocity field. In the Delaware, the mean surface Stokes velocity was $0.16 \mathrm{~m} / \mathrm{s}$ on shallow flats and $0.18 \mathrm{~m} / \mathrm{s}$ in relatively deeper areas of the lower bay (Figure 10), similar to the results of the idealized model assessment (Figure 5b) and consistent with Kenyon (1969) who reported that the magnitude of the surface Stokes drift is $1 \%$ to $3 \%$ of the wind speed. Since the Stokes velocity drops exponentially in the vertical, the associated water mass transport was confined to the upper $10-15 \%$ of the water column (vertical e-folding scale $\sim 1.5 \mathrm{~m}$ ). The model also indicates weak tidal modulation (about $10 \%$ ) of the Stokes drift in the basin given the modest response of the wave field to currents, especially in the deep channel.

The leading order momentum terms in the bay are the surface stress, pressure gradient force and, to a lesser extent, bottom stress (SSTR, PGF, and BSTR) during the modeled wind event. Their spatial distribution is shown in Figure 11 for the scenarios with and without waves. In the case with no waves, the SSTR term was modulated by topography given its inverse relationship with depth $\left(\tau_{s} / \rho h\right)$, and its magnitude was $\sim 1.5 \times 10^{-4} \mathrm{~m} / \mathrm{s}^{2}$ in shallow shoals and $\sim 0.5 \times 10^{-4} \mathrm{~m} / \mathrm{s}^{2}$ in the deeper channel. When waves were considered, the SSTR magnitude increased by a factor of 1.1-1.3, consistent with the increase in surface drag presented in section 4.1. The spatial pattern of PGF mirrored the SSTR with nearly similar values, which suggests that the main momentum balance was between these two terms. As a result, the increase in SSTR under wind waves was reflected in an adjustment in the PGF, which also increased by factors between 1.1 and 1.3 with respect to the run with no waves (Figure 11, bottom row). The along-thalweg mean elevation increased by about $11 \%$ (0.66 to $0.72 \mathrm{~m}$ over the thalweg length, $220 \mathrm{~km}$ ).

The phase-averaged momentum equations in the vortex force formalism ((6) and (7)) indicate that waves can also contribute to the PGF by incorporating the gradient of the quasi-static elevation and of the Bernoulli head, neither of which were significant here. The BSTR term was on the same order of magnitude as the SSTR and PGF, but it was comparatively small throughout the basin, and its magnitude did not exceed $0.5 \times 10^{-4} \mathrm{~m} / \mathrm{s}^{2}$ on shallow shoals and $0.16 \times 10^{-4} \mathrm{~m} / \mathrm{s}^{2}$ in the deep channel for the uncoupled run. The BSTR increment factor under waves was $\sim 1.2-1.3$, mainly in relatively shallow areas and shoals, but the leading balance between PGF and SSTR still held for most of the basin.

The spatial distribution of horizontal vortex forces, breaking forces, and Stokes-Coriolis forces (HJVF, BRK, and StkCOR) is shown in Figure 12. Vortex forces were present in areas of relatively high lateral shear (i.e., along the edges of linear ridges and at bathymetric transitions from shoals to deeper channels), but the overall contribution to the budget was modest and an order of magnitude smaller than the leading order terms. The StkCOR term, which scales with $f u_{s t} / h \approx 10^{-4} \cdot 10^{-1} / 10^{0}=10^{-6} \mathrm{~m} / \mathrm{s}^{2}$, was also small compared to leading order $\mathrm{O}\left(10^{-4} \mathrm{~m} / \mathrm{s}^{2}\right)$ terms. In contrast, breaking forces were $\mathrm{O}\left(10^{-4} \mathrm{~m} / \mathrm{s}^{2}\right)$ on highly localized shallow ridges and nearshore regions in the lower bay and zero in the rest of the basin. As described previously, the magnitude of the BRK term only depends on the depth-limited wave breaking dissipation $\left(S_{\mathrm{br}}\right)$, which 

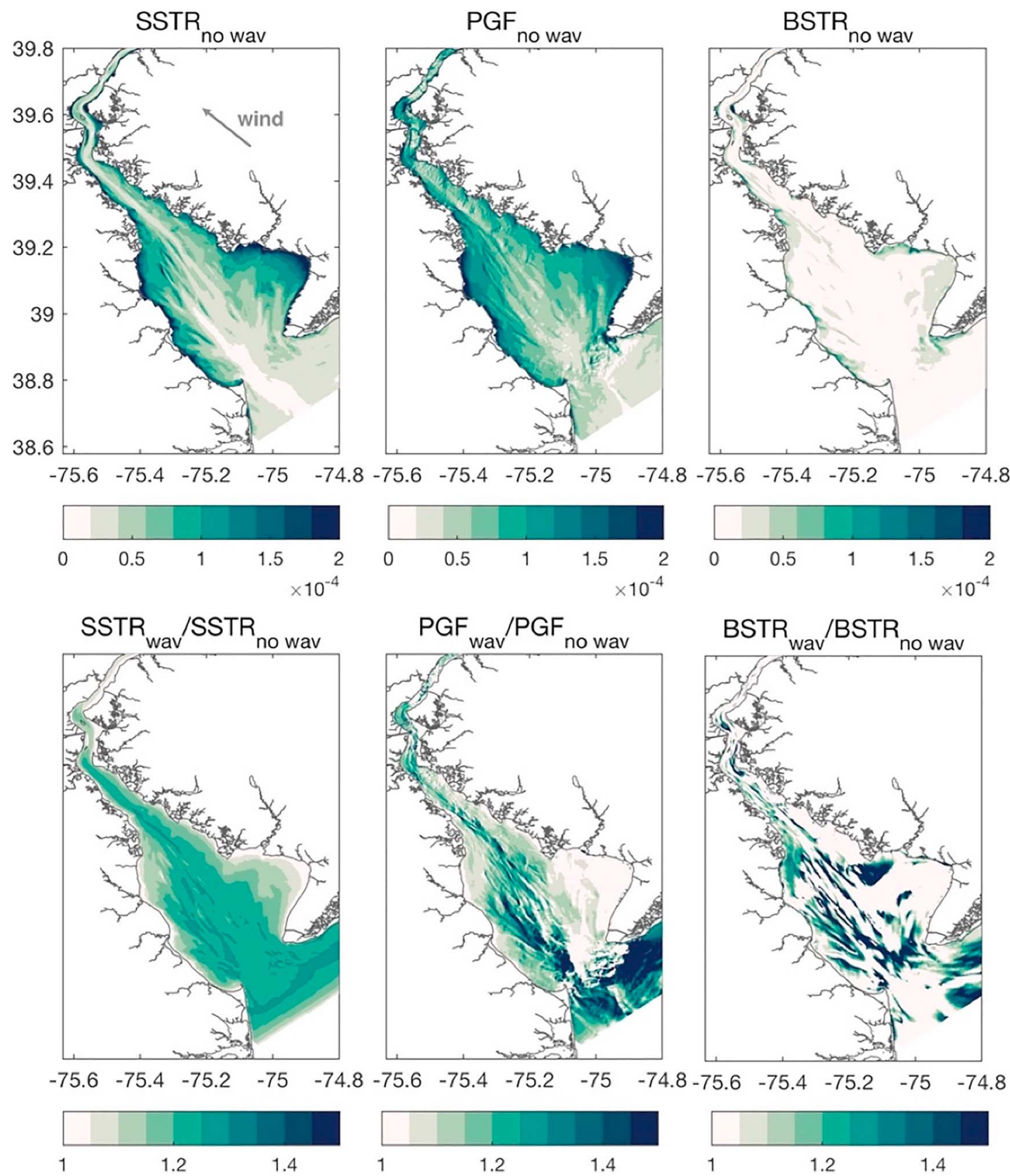

Figure 11. Leading order momentum balance terms in the bay. (top row) Tidally and depth-averaged surface stress, pressure gradient force, and bottom stress terms (SSTR, PGF, and BSTR, respectively) in the scenario of up-estuary winds with no waves. (bottom row) Increment factor for each term when waves are included in the model. The magnitude of each term is color coded $\left(\mathrm{m} / \mathrm{s}^{2}\right)$.

is a function of the topographically constrained factor $\beta=H_{\mathrm{rms}} / \gamma h$ ( $\gamma=0.8$ is the breaker parameter). According to the bore model by Battjes and Janssen (1978) used in this study, the fraction of depth-limited breaking waves is set to zero on grid points where $\beta \leq 0.2$. Values of $\beta$ in Delaware Bay during the simulated storms range from 0.05 in the channel and 0.15 on shallow flats, which explains the highly localized spatial distribution of the breaking term.

Analysis of the momentum budget with and without waves indicates that even if wave-induced forces are small in shallow basins, waves can impact the mean momentum budget by altering drag and by incorporating Stokes drift to the velocity field. The role of waves on drag can be important in systems such as Delaware Bay because of the broad spatial distribution of the wave height and age. The Delaware differs from other 

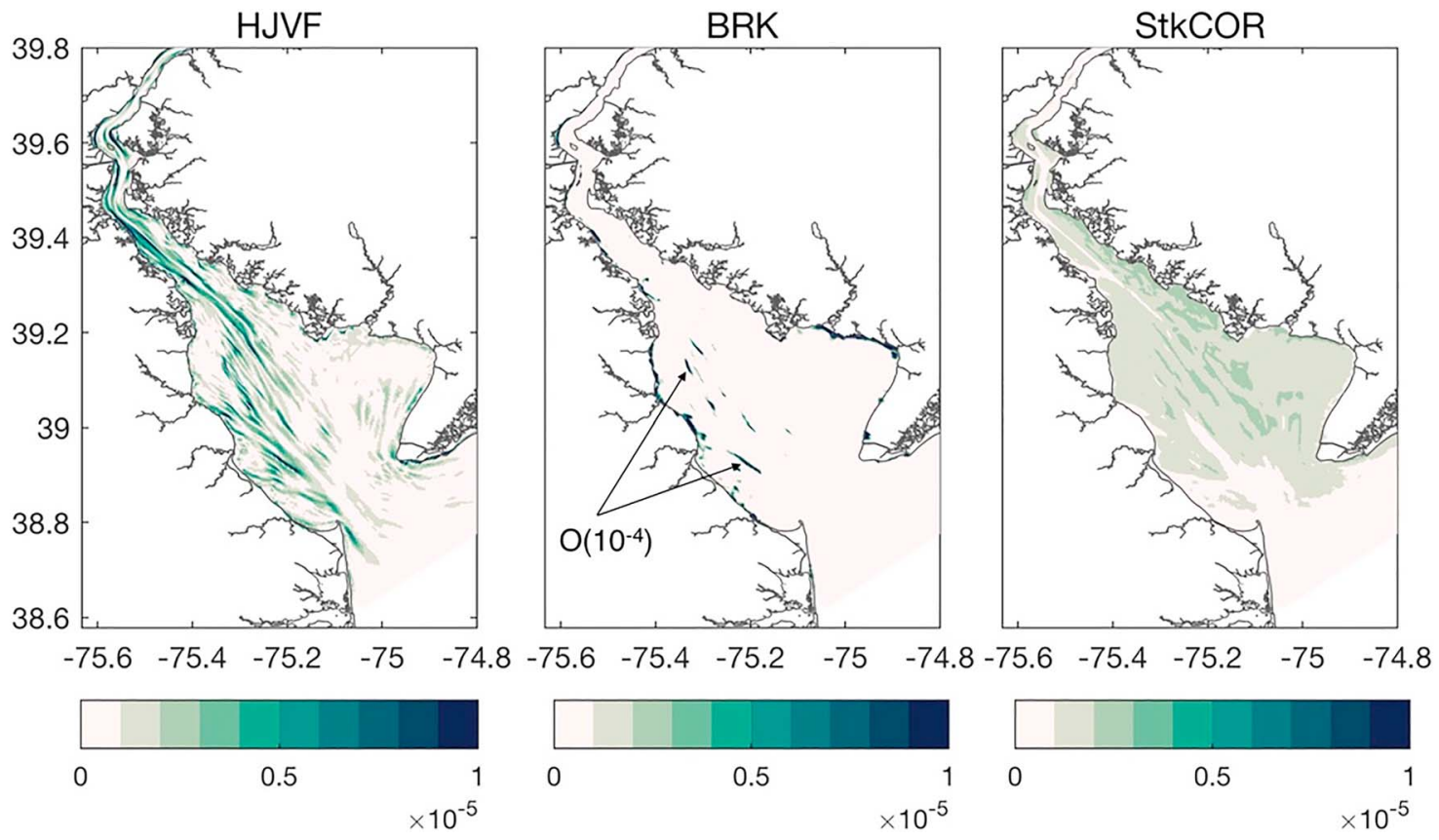

Figure 12. Wave-induced momentum budget terms in the bay: horizontal vortex forces, breaking force, and Stokes-Coriolis force (HJVF, BRK, and StkCOR, respectively). The magnitude of each term is color coded $\left(\mathrm{m} / \mathrm{s}^{2}\right)$. Note these terms are $\sim \mathrm{O}\left(10^{-5}\right)$.

coastal systems such as back-barrier estuaries, tidal inlets, and coral reefs (see, e.g., Beudin et al., 2017; Olabarrieta et al., 2014, 2011; Rogers et al., 2017; Uchiyama et al., 2010) in that that waves are mainly local and wind-generated instead of remote (Chen et al., 2018) and in that the bathymetric distribution is the result of both natural and anthropogenic processes. The latter leads to distinct patterns in the wavedriven momentum budget. Steep bathymetric transitions from shoals to dredged channels generate velocity gradients that interact with the Stokes drift to create local vortex forces. In the Delaware, wave breaking forces are zero at the relatively deep mouth (>20 m deep, $20 \mathrm{~km}$ wide) and are only important on shallow, linear ridges inside the embayment due to local waves. The opposite is true, for example, in New River inlet where the mouth is relatively shallow ( $5 \mathrm{~m}$ deep, $1 \mathrm{~km}$ wide), which forces remote waves to break and inject momentum to the water column, enhancing subtidal flows (Wargula et al., 2014).

\subsection{Subtidal Exchange}

While the contribution of Stokes-Coriolis, breaking, and vortex forces to the mean budget was modest, now we explore how subtidal flows can change mainly due to the increases in surface drag and the inclusion of Stokes drift. In this section, we consider all benchmark and coupled runs since the residual patterns are sensitive to wind direction (up and down-estuary winds, with and without waves). The horizontal transport (cubic meters per second) was calculated in northward $\left(T_{\mathrm{N}}\right)$ and eastward $\left(T_{\mathrm{E}}\right)$ components at each grid point through the product of the depth-dependent velocity, the fixed grid cell width $(\Delta x, \Delta y)$, and the time-varying vertical thickness $(\delta)$ according to

$$
\begin{aligned}
& T_{\mathrm{E}}(x, y, t)=\sum_{i=1}^{20} u_{i \mathrm{E}}^{l}(x, y, z, t) \delta_{i}(x, y, z, t) \Delta y, \\
& T_{\mathrm{N}}(x, y, t)=\sum_{i=1}^{20} u_{i \mathrm{~N}}^{l}(x, y, z, t) \delta_{i}(x, y, z, t) \Delta x,
\end{aligned}
$$

where $u_{i \mathrm{E}}^{l}$ and $u_{i \mathrm{~N}}^{l}$ are the eastward and northward Lagrangian velocities at the $i$ th layer, respectively, and the summation is performed over the 20 vertical levels. This method calculates the transport by following the time-varying water column thickness instead of utilizing the resting basin depth. To compute the residual exchange, each component was averaged over the duration of the wind event (5 days), and the results are shown in Figure 13 for the spatial patterns and in Figure 14 for the mean transport through two cross sections of the bay. 

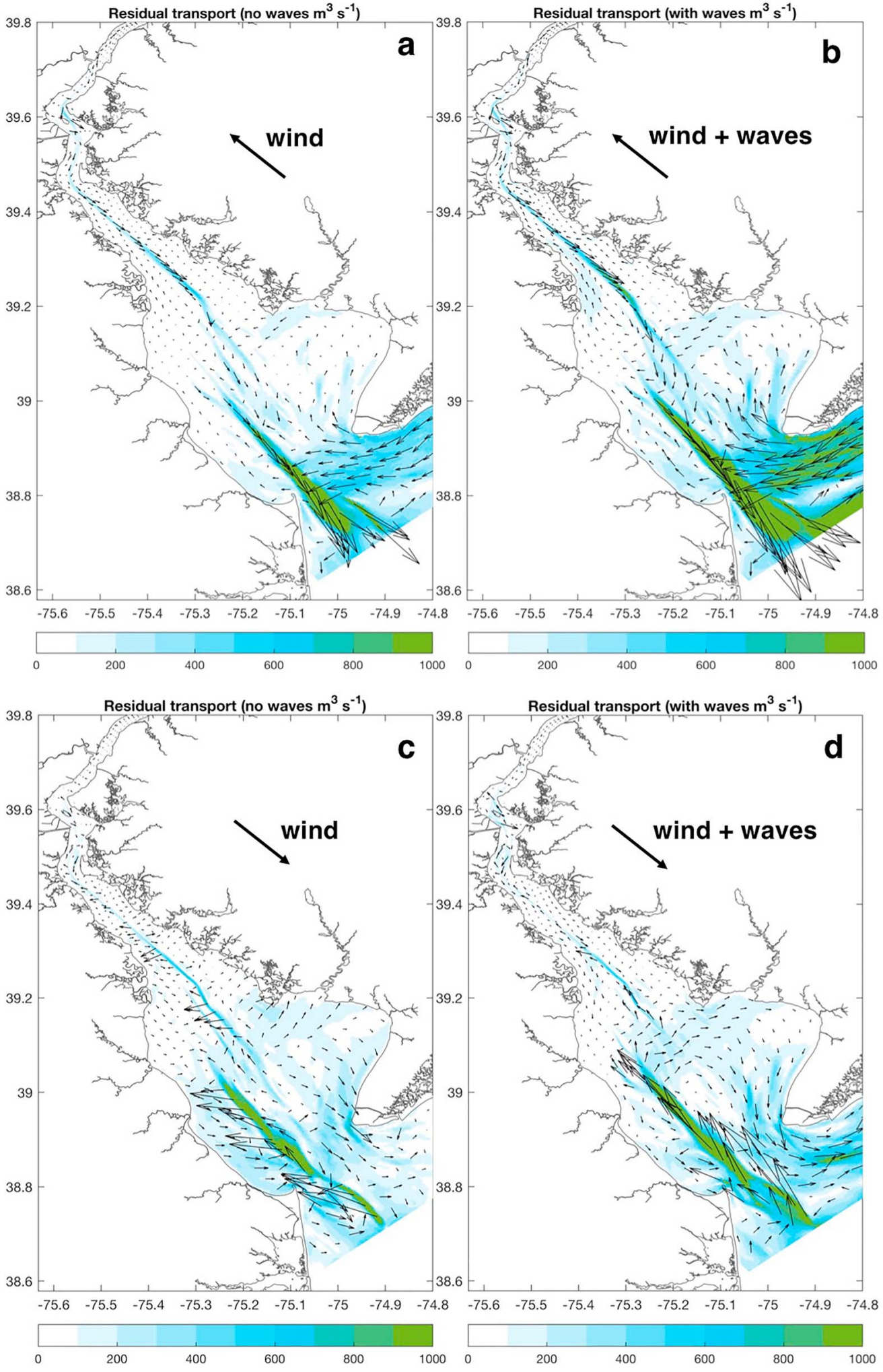

Figure 13. Modeled residual circulation (arrows) for the up-estuary (a, b) and down-estuary wind and wind-wave scenarios (c, d). Residual transport magnitude is shown in colors. 

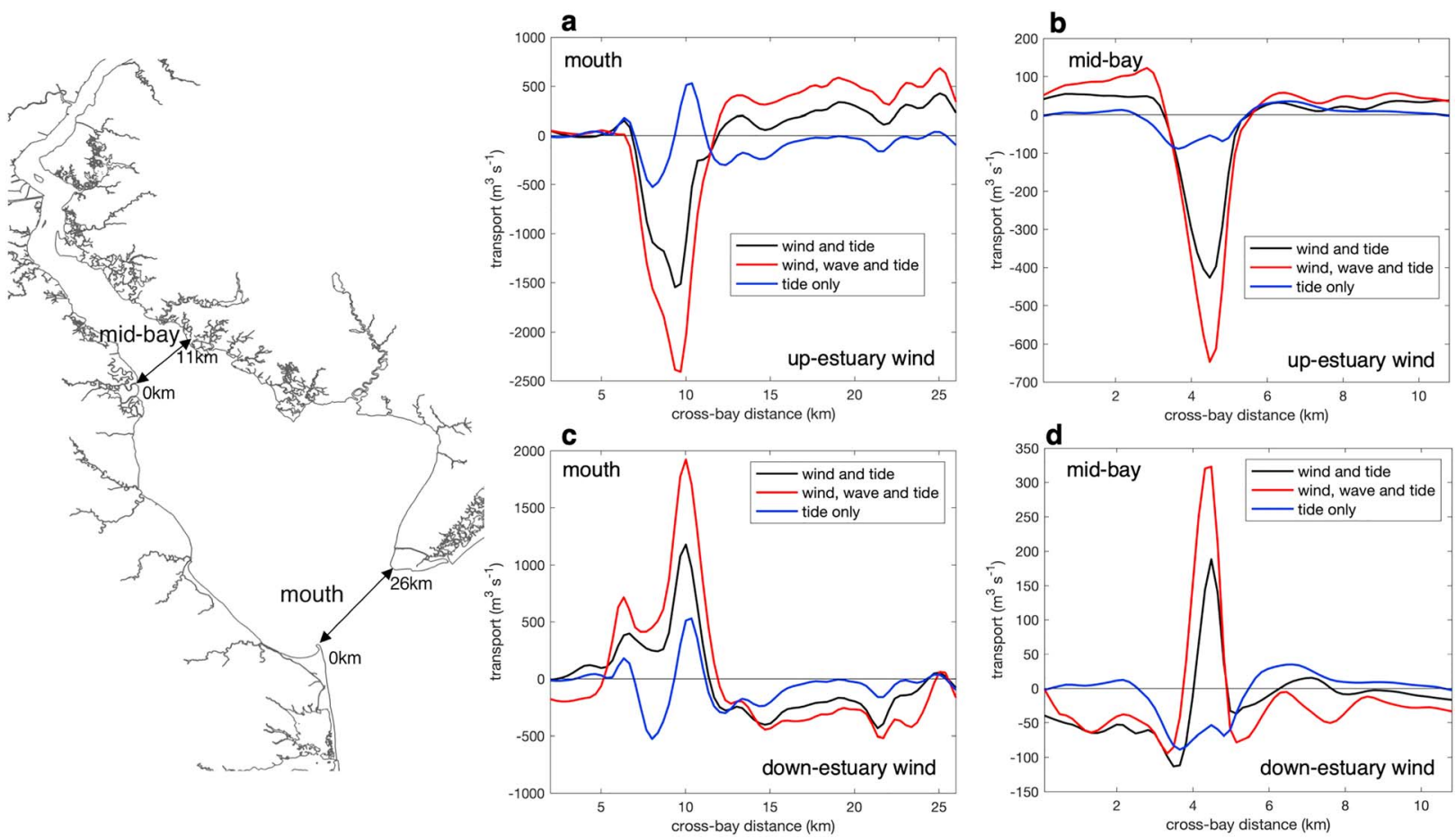

Figure 14. Depth-integrated residual exchange at two cross-bay transects for the modeled up-estuary (a, b) and down-estuary (c, d) wind scenarios. Transect locations are shown on the map. Transport values are plotted for the coupled scenario (wind, wave, and tide) and for the uncoupled one (wind and tide). The residual transport in the absence of wind and waves (labeled as "tide-only") is shown in all panels for reference.

For the up-estuary wind-only scenario, the subtidal transport features a laterally sheared circulation with inflow in the flanks and outflow in the deeper channels. The obtained laterally sheared mean flow is consistent with the expected residual pattern in a long basin with tides (C. Y. Li \& O'Donnell, 2005; Winant, 2008) and in a shallow, wind-driven basin with sloping bathymetry where the flow is downwind in the shallows and upwind in the channel (Csanady, 1973; Signell et al., 1990). The subtidal bay-ocean exchange here is facilitated by a counterclockwise gyre in the lower bay. When waves are incorporated to the up-estuary wind scenario (Figure 13b), the subtidal inflow and outflow increase by a factor of 1.2-1.5. This increase can also be seen in Figure 14 where the residual transport under wind waves across the middle and lower bay was 1.2-1.5 times the transport obtained in the wind-only cases. The role of waves in this departure can be explained mainly by the adjustment of the pressure gradient force to the increased surface stress and by the up-estuary wave-induced Stokes transport.

In the down-estuary wind scenario (Figure 13c), the transport pattern indicates inflow in the deep thalweg and outflow in the flanks, and the subtidal exchange magnitude is smaller than in the case with up-estuary winds by nearly $30 \%$. Note that in the up-estuary wind case, the wind-driven flow enhances the tidal residual circulation (i.e., both lead to inflow in shallow water and outflow in the channel), while the down-estuary wind driven circulation is in the opposite direction of the tidal residual. When waves are included in the down-estuary wind case (Figure 13d), the magnitude of the exchange increases in response to the adjustment between PGF and SSTR. However, that increase in magnitude was not as noticeable as in the upestuary wind-wave case since the wind-driven circulation still goes against the direction of the tidal residual. For example, the peak transport in the thalweg was $\sim 2,500 \mathrm{~m}^{3} / \mathrm{s}$ for the up-estuary wind-wave case and about $2,000 \mathrm{~m}^{3} / \mathrm{s}$ for the down-estuary wind-wave case.

\section{Summary and Conclusions}

In this work we used a numerical model to assess the impact of wind-generated waves on boundary layer stresses, wave-induced forces, and residual circulation in shallow coastal plain estuaries with Delaware Bay as a generalizable example. An assessment of the vortex force formalism in an idealized basin was 
performed to explore the impact of wave energy dissipation on circulation. Model results suggest that the whitecapping-induced breaking force double counts the contribution of the wind stress in the Reynoldsaveraged momentum budget. Therefore, we altered the original model formulation to prevent whitecapping from generating breaking forces. This modification is consistent with previous studies on nearshore currents and with additional options to compute breaking forces in the model, which only consider the depth-limited breaking dissipation for the force. Instead, we considered the impact of waves on the surface drag coefficient by using a parameterization that is suitable for young, wind-driven seas where the wave field evolution is limited by local topography. When a wave-induced surface drag formulation was employed, the drag coefficient increased by a factor of 1.3 with respect to a drag coefficient that is only a function of wind speed. While "bulk" surface drag formulations have been extensively used for a range of marine environments, here we show that they do not capture the spatial variability that has been reported in previous observational studies of air-sea fluxes in estuaries and similar fetch-limited environments. In estuaries such as Delaware Bay, the impact of waves on surface drag is significant for subtidal exchange at storm time scales. Tidally averaged horizontal transport patterns differ by a factor up to 1.5 when waves are included and are sensitive to wind direction. Regarding the momentum budget, vortex forces were present at bathymetric transitions from shoals to channels given their dependency on velocity gradients, but their contribution to the budget was quite modest and an order of magnitude smaller than the leading order terms (surface stress, bottom stress, and pressure gradient). Stokes-Coriolis forces were also negligible and did not significantly contribute to the mean budget. The breaking force (i.e., from depth-limited breaking dissipation) term was leading order only on steep ridges in the lower bay; therefore, its net impact in the basin momentum distribution was also small. Results here motivate the consideration of wave coupling and the usage of a suitable wave-induced surface drag coefficient formulation in studies of storm-driven circulation in estuaries.

\section{Acknowledgments}

This work was supported by National Science Foundation Coastal SEES grant 1325136. We acknowledge Christopher Sommerfield's Group, Jia-Lin Chen, and Julia Levin who provided assistance with the model configuration. We also thank Nirnimesh Kumar, Greg Gerbi, Melissa Moulton, and the Rutgers Ocean Modeling group for constructive feedback. Insightful comments by two anonymous reviewers helped improve the manuscript. Model files are available in an open access repository (https://doi.org/10.5281/ zenodo.1695900).

\section{References}

Aiki, H., \& Greatbatch, R. J. (2014). A new expression for the form stress term in the vertically Lagrangian mean framework for the effect of surface waves on the upper-ocean circulation. Journal of Physical Oceanography, 44(1), 3-23. https://doi.org/10.1175/Jpo-D-12-0228.1

Ardhuin, F., Chapron, B., \& Elfouhaily, T. (2004). Waves and the air-sea momentum budget: Implications for ocean circulation modeling. Journal of Physical Oceanography, 34(7), 1741-1755. https://doi.org/10.1175/1520-0485(2004)034<1741:Watamb>2.0.Co;2

Battjes, J. A., \& Janssen, P. F. M. (1978). Energy loss and set-up due to breaking of random waves. Coastal Engineering, 1978.

Beudin, A., Ganju, N. K., Defne, Z., \& Aretxabaleta, A. L. (2017). Physical response of a back-barrier estuary to a post-tropical cyclone. Journal of Geophysical Research: Oceans, 122, 5888-5904. https://doi.org/10.1002/2016jc012344

Booij, N., Ris, R. C., \& Holthuijsen, L. H. (1999). A third-generation wave model for coastal regions-1. Model description and validation. Journal of Geophysical Research, 104(C4), 7649-7666. https://doi.org/10.1029/98jc02622

Bricker, J. D. (2003). Bed drag coefficient variability under wind waves in a tidal estuary: Field measurements and numerical modeling. In S. G. Monismith (Ed.).

Bricker, J. D., Inagaki, S., \& Monismith, S. G. (2004). Modelling the effects of bed drag coefficient variability under wind waves in South San Francisco Bay. Estuarine and Coastal Modeling, Proceedings, 89-107.

Carniel, S., Warner, J. C., Chiggiato, J., \& Sclavo, M. (2009). Investigating the impact of surface wave breaking on modeling the trajectories of drifters in the northern Adriatic Sea during a wind-storm event. Ocean Modelling, 30(2-3), 225-239. https://doi.org/10.1016/j. ocemod.2009.07.001

Cavaleri, L., \& Malanotte-Rizzoli, P. (1981). Wind wave prediction in shallow water: Theory and applications. Journal of Geophysical Research, 86(C11), 10,961-10,973. https://doi.org/10.1029/JC086iC11p10961

Charnock, H. (1955). Wind stress on a water surface. Quarterly Journal of the Royal Meteorological Society, 81(350), 639-640. https://doi. org/10.1002/qj.49708135027

Chen, J.-L., Ralston, D. K., Geyer, W. R., Sommerfield, C. K., \& Chant, R. J. (2018). Wave generation, dissipation, and disequilibrium in an embayment with complex bathymetry. Journal of Geophysical Research: Oceans, 123, 7856-7876. https://doi.org/10.1029/ 2018JC014381

Cho, H. J. (2007). Effects of prevailing winds on turbidity of a shallow estuary. International Journal of Environmental Research and Public Health, 4(2), 185-192. https://doi.org/10.3390/ijerph2007040014

Church, J. C., \& Thornton, E. B. (1993). Effects of breaking wave induced turbulence within a longshore current model. Coastal Engineering, 20(1), 1-28. https://doi.org/10.1016/0378-3839(93)90053-B

Craig, P. D., \& Banner, M. L. (1994). Modeling wave-enhanced turbulence in the ocean surface layer. Journal of Physical Oceanography, 24(12), 2546-2559. https://doi.org/10.1175/1520-0485(1994)024<2546:mwetit>2.0.co;2

Craik, A. D. D., \& Leibovich, S. (1976). A rational model for Langmuir circulations. Journal of Fluid Mechanics, 73(3), 401-426. https://doi. org/10.1017/S0022112076001420

Csanady, G. T. (1973). Wind-induced barotropic motions in Long Lakes. Journal of Physical Oceanography, 3(4), 429-438. https://doi.org/ 10.1175/1520-0485(1973)003<0429:wibmil >2.0.co;2

Dean, R. G., \& Dalrymple, R. A. (2001). Coastal processes with engineering applications. Cambridge: Cambridge University Press. https:// doi.org/10.1017/CBO9780511754500

DiLorenzo, J., Huang, P., Uewellyn Thatcher, M., Najarian, T. O., \& Asce, M. (1993). Dredging impacts of Delaware estuary tides.

Dingemans, M. W., Radder, A. C., \& De Vriend, H. J. (1987). Computation of the driving forces of wave-induced currents. Coastal Engineering, 11(5), 539-563. https://doi.org/10.1016/0378-3839(87)90026-3

Donelan, M. A. (1990). Air-sea interaction. In B. Le Mehaute \& D. M. Hanes (Eds.), The sea (Vol. 9, pp. 239-292). New York: John Wiley. 
Donelan, M. A., Hamilton, J., \& Hui, W. (1985). Directional spectra of wind-generated ocean waves. Philosophical Transactions of the Royal Society of London. Series A. Mathematical and Physical Sciences, 315(1534), 509. https://doi.org/10.1098/rsta.1985.0054

Drennan, W. M., Graber, H. C., Hauser, D., \& Quentin, C. (2003). On the wave age dependence of wind stress over pure wind seas. Journal of Geophysical Research, 108(C3), 8062. https://doi.org/10.1029/2000JC000715

Drennan, W. M., Taylor, P. K., \& Yelland, M. J. (2005). Parameterizing the sea surface roughness. Journal of Physical Oceanography, 35(5), 835-848. https://doi.org/10.1175/Jpo2704.1

Dzwonkowski, B., Wong, K. C., \& Ullman, W. J. (2014). Water level and velocity characteristics of a salt marsh channel in the Murderkill Estuary, Delaware. Journal of Coastal Research, 30(1), 63-74. https://doi.org/10.2112/Jcoastres-D-12-00161.1

Edson, J. B., Jampana, V., Weller, R. A., Bigorre, S. P., Plueddemann, A. J., Fairall, C. W., et al. (2013). On the exchange of momentum over the Open Ocean. Journal of Physical Oceanography, 43(8), 1589-1610. https://doi.org/10.1175/JPO-D-12-0173.1

Elsey-Quirk, T. (2016). Impact of Hurricane Sandy on salt marshes of New Jersey. Estuarine, Coastal and Shelf Science, 183, 235-248. https://doi.org/10.1016/j.ecss.2016.09.006

Fairall, C. W., Bradley, E. F., Hare, J. E., Grachev, A. A., \& Edson, J. B. (2003). Bulk parameterization of air-sea fluxes: Updates and verification for the COARE algorithm. Journal of Climate, 16(4), 571-591. https://doi.org/10.1175/1520-0442(2003)016<0571: Bpoasf $>2.0 . \mathrm{Co} ; 2$

Fairall, C. W., Bradley, E. F., Rogers, D. P., Edson, J. B., \& Young, G. S. (1996). Bulk parameterization of air-sea fluxes for Tropical Ocean Global Atmosphere Coupled Ocean Atmosphere Response Experiment. Journal of Geophysical Research, 101(C2), 3747-3764. https:// doi.org/10.1029/95jc03205

Fisher, A. W., Sanford, L. P., Scully, M. E., \& Suttles, S. E. (2017). Surface wave effects on the translation of wind stress across the air-sea interface in a fetch-limited, coastal embayment. Journal of Physical Oceanography, 47(8), 1921-1939. https://doi.org/10.1175/JPO-D-160146.1

Fisher, A. W., Sanford, L. P., \& Suttles, S. E. (2015). Wind stress dynamics in Chesapeake Bay: Spatiotemporal variability and wave dependence in a fetch-limited environment. Journal of Physical Oceanography, 45(10), 2679-2696. https://doi.org/10.1175/Jpo-D-150004.1

Friedrichs, C. T., \& Aubrey, D. G. (1994). Tidal propagation in strongly convergent channels. Journal of Geophysical Research, 99(C2), 3321-3336. https://doi.org/10.1029/93jc03219

Garcia-Nava, H., Ocampo-Torres, F. J., \& Hwang, P. A. (2012). On the parameterization of the drag coefficient in mixed seas. Scientia Marina, 76(S1), 177-186. https://doi.org/10.3989/scimar.03615.19F

Garvine, R. W. (1985). A simple model of estuarine subtidal fluctuations forced by local and remote wind stress. Journal of Geophysical Research, 90(C6), 11945-11948. https://doi.org/10.1029/JC090iC06p11945

Geyer, W. R. (1997). Influence of wind on dynamics and flushing of shallow estuaries. Estuarine, Coastal and Shelf Science, 44(6), 713-722. https://doi.org/10.1006/ecss.1996.0140

Grant, W. D., \& Madsen, O. S. (1982). Movable bed roughness in unsteady oscillatory flow. Journal of Geophysical Research, 87(C1), 469-481 . https://doi.org/10.1029/JC087iC01p00469

Henrie, K., \& Valle-Levinson, A. (2014). Subtidal variability in water levels inside a subtropical estuary. Journal of Geophysical Research: Oceans, 119, 7483-7492. https://doi.org/10.1002/2014jc009829

Holthuijsen, L. H. (2007). Waves in oceanic and coastal waters. Cambridge: Cambridge University Press. https://doi.org/10.1017/ CBO9780511618536

Holthuijsen, L. H. (2010). Waves in oceanic and coastal waters. Cambridge: Cambridge University Press.

Hughes, C. P., \& Veron, D. E. (2015). Characterization of low-level winds of southern and coastal Delaware. Journal of Applied Meteorology and Climatology, 54(1), 77-93. https://doi.org/10.1175/jamc-d-14-0011.1

Hunter, J. R., \& Hearn, C. J. (1987). Lateral and vertical variations in the wind-driven circulation in Long, Shallow Lakes. Journal of Geophysical Research, 92(C12), 13,106-13,114. https://doi.org/10.1029/JC092iC12p13106

Jackson, N. L. (1995). Wind and waves-Influence of local and nonlocal waves on mesoscale beach behavior in estuarine environments. Annals of the Association of American Geographers, 85(1), 21-37.

Jenkins, R. L., III. (2015). Surface wave analysis based on a hydrodynamic modeling system for the Delaware coastal environment. (1596864 M.S.), University of Delaware, Ann Arbor. ProQuest Dissertations \& Theses Global database.

Johnson, H. K., \& Vested, H. J. (1992). Effects of water waves on wind shear stress for current modeling. Journal of Atmospheric and Oceanic Technology, 9(6), 850-861. https://doi.org/10.1175/1520-0426(1992)009<0850:Eowwow >2.0.Co;2

Jones, N. L., \& Monismith, S. G. (2008). The influence of whitecapping waves on the vertical structure of turbulence in a shallow estuarine embayment. Journal of Physical Oceanography, 38(7), 1563-1580. https://doi.org/10.1175/2007jpo3766.1

Kenyon, K. (1969). Stokes drift for random gravity waves. Journal of Geophysical Research, 74(28), 6991-6994. https://doi.org/10.1029/ JC074i028p06991

Kitaigorodskii, S. A. (1973). The physics of air-sea interaction. Jerusalem: Israel Program for Scientific Translations.

Komen, G. J., Hasselmann, K., \& Hasselmann, K. (1984). On the existence of a fully developed wind-sea spectrum. Journal of Physical Oceanography, 14(8), 1271-1285. https://doi.org/10.1175/1520-0485(1984)014<1271:OTEOAF >2.0.CO;2

Kukulka, T., Jenkins, R. L., Kirby, J. T., Shi, F., \& Scarborough, R. W. (2017). Surface wave dynamics in Delaware Bay and its adjacent coastal shelf. Journal of Geophysical Research: Oceans, 122, 8683-8706. https://doi.org/10.1002/2017JC013370

Kumar, N., Voulgaris, G., \& Warner, J. C. (2011). Implementation and modification of a three-dimensional radiation stress formulation for surf zone and rip-current applications. Coastal Engineering, 58(12), 1097-1117. https://doi.org/10.1016/j coastaleng.2011.06.009

Kumar, N., Voulgaris, G., Warner, J. C., \& Olabarrieta, M. (2012). Implementation of the vortex force formalism in the Coupled OceanAtmosphere-Wave-Sediment Transport (COAWST) modeling system for inner shelf and surf zone applications. Ocean Modelling, 47, 65-95. https://doi.org/10.1016/j.ocemod.2012.01.003

Large, W. G., \& Pond, S. (1981). Open ocean momentum flux measurements in moderate to strong winds. Journal of Physical Oceanography, 11(3), 324-336. https://doi.org/10.1175/1520-0485(1981)011<0324:Oomfmi >2.0.Co;2

Levin, J., Wilkin, J., Fleming, N., \& Zavala-Garay, J. (2018). Mean circulation of the Mid-Atlantic Bight from a climatological data assimilative model. Ocean Modelling, 128, 1-14. https://doi.org/10.1016/j.ocemod.2018.05.003

Li, C. Y., \& O'Donnell, J. (2005). The effect of channel length on the residual circulation in tidally dominated channels. Journal of Physical Oceanography, 35(10), 1826-1840. https://doi.org/10.1175/Jpo2804.1

Li, M., Zhong, L., Boicourt, W. C., Zhang, S., \& Zhang, D.-L. (2006). Hurricane-induced storm surges, currents and destratification in a semi-enclosed bay. Geophysical Research Letters, 33, L02604. https://doi.org/10.1029/2005GL024992 
Longuet-Higgins, M. S., \& Stewart, R. W. (1964). Radiation stresses in water waves; a physical discussion, with applications. Deep Sea Research and Oceanographic Abstracts, 11(4), 529-562. https://doi.org/10.1016/0011-7471(64)90001-4

Luettich, R. A., Westerink, J. J., \& Scheffner, N. W. (1992). ADCIRC: An advanced three-dimensional circulation model for shelves, coasts and estuaries. Report 1: Theory and methodology of ADCIRC-2DDI and ADCIRC-3DL Dredging Research Program. Tehcnical Report DRP-92-6 (pp. 173). Vickburg, Miss: U.S. Army Corps of Engineers.

Madsen, O. S., Poon, Y.-K., \& Graber, H. C. (1988). Spectral wave attenuation by bottom friction: Theory. Coastal Engineering Proceedings, 1(21), 492-504. https://doi.org/10.9753/icce.v21.\%p

McSweeney, J. M., Chant, R. J., \& Sommerfield, C. K. (2016). Lateral variability of sediment transport in the Delaware Estuary. Journal of Geophysical Research: Oceans, 121, 725-744. https://doi.org/10.1002/2015jc010974

McSweeney, J. M., Chant, R. J., Wilkin, J. L., \& Sommerfield, C. K. (2016). Suspended-sediment impacts on light-limited productivity in the Delaware Estuary. Estuaries and Coasts https://doi.org/10.1007/s12237-016-0200-3, 40(4), 977-993.

McWilliams, J. C., Restrepo, J. M., \& Lane, E. M. (2004). An asymptotic theory for the interaction of waves and currents in coastal waters. Journal of Fluid Mechanics, 511, 135-178. https://doi.org/10.1017/s0022112004009358

Mellor, G. (2010). Wave radiation stress. Ocean Dynamics, 61(5), 563-568. https://doi.org/10.1007/s10236-010-0359-2

Nepf, H. M., \& Monismith, S. G. (1991). Experimental-study of wave-induced longitudinal vortices. Journal of Hydraulic Engineering-Asce, 117(12), 1639-1649. https://doi.org/10.1061/(Asce)0733-9429(1991)117:12(1639)

Olabarrieta, M., Geyer, W. R., \& Kumar, N. (2014). The role of morphology and wave-current interaction at tidal inlets: An idealized modeling analysis. Journal of Geophysical Research: Oceans, 119, 8818-8837. https://doi.org/10.1002/2014jc010191

Olabarrieta, M., Warner, J. C., Armstrong, B., Zambon, J. B., \& He, R. Y. (2012). Ocean-atmosphere dynamics during Hurricane Ida and Nor'Ida: An application of the coupled ocean-atmosphere-wave-sediment transport (COAWST) modeling system. Ocean Modelling, 4344, 112-137. https://doi.org/10.1016/j.ocemod.2011.12.008

Olabarrieta, M., Warner, J. C., \& Kumar, N. (2011). Wave-current interaction in Willapa Bay. Journal of Geophysical Research, 116, C12014. https://doi.org/10.1029/2011jc007387

Oost, W. A., Komen, G. J., Jacobs, C. M. J., \& van Oort, C. (2002). New evidence for a relation between wind stress and wave age from measurements during ASGAMAGE. Boundary-Layer Meteorology, 103(3), 409-438. https://doi.org/10.1023/A:1014913624535

Ortiz-Suslow, D. G., Haus, B. K., Williams, N. J., Laxague, N. J. M., Reniers, A. J. H. M., \& Graber, H. C. (2015). The spatial-temporal variability of air-sea momentum fluxes observed at a tidal inlet. Journal of Geophysical Research: Oceans, 120, 660-676. https://doi.org/ $10.1002 / 2014$ jc010412

Perrie, W., Tang, C. L., Hu, Y., \& DeTracy, B. M. (2003). The impact of waves on surface currents. Journal of Physical Oceanography, 33(10), 2126-2140. https://doi.org/10.1175/1520-0485(2003)033<2126:Tiowos > 2.0.Co;2

Rogers, J. S., Monismith, S. G., Fringer, O. B., Koweek, D. A., \& Dunbar, R. B. (2017). A coupled wave-hydrodynamic model of an atoll with high friction: Mechanisms for flow, connectivity, and ecological implications. Ocean Modelling, 110, 66-82. https://doi.org/10.1016/j. ocemod.2016.12.012

Sanay, R., \& Valle-Levinson, A. (2005). Wind-induced circulation in semienclosed homogeneous, rotating basins. Journal of Physical Oceanography, 35(12), 2520-2531. https://doi.org/10.1175/Jpo2831.1

Savtchenko, A., Tang, S., Barber, R., \& Wu, J. (1999). Air-sea interaction processes at light winds observed from a coastal tower. Journal of Coastal Research, 15(2), 444-456.

Scully, M. E., Friedrichs, C., \& Brubaker, J. (2005). Control of estuarine stratification and mixing by wind-induced straining of the estuarine density field. Estuaries, 28(3), 321-326. https://doi.org/10.1007/Bf02693915

Scully, M. E., Geyer, W. R., \& Lerczak, J. A. (2009). The influence of lateral advection on the residual estuarine circulation: A numerical modeling study of the Hudson River Estuary. Journal of Physical Oceanography, 39(1), 107-124. https://doi.org/10.1175/2008jpo3952.1

Scully, M. E., Trowbridge, J. H., Sherwood, C. R., Jones, K. R., \& Traykovski, P. (2018). Direct measurements of mean Reynolds stress and ripple roughness in the presence of energetic forcing by surface waves. Journal of Geophysical Research: Oceans, 123, 2494-2512. https:// doi.org/10.1002/2017JC013252

Shchepetkin, A. F., \& McWilliams, J. C. (2005). The Regional Oceanic Modeling System (ROMS): A split-explicit, free-surface, topography following-coordinate oceanic model. Ocean Modelling, 9(4), 347-404. https://doi.org/10.1016/j.ocemod.2004.08.002

Signell, R. P., Beardsley, R. C., Graber, H. C., \& Capotondi, A. (1990). Effect of wave-current interaction on wind-driven circulation in narrow, shallow embayments. Journal of Geophysical Research, 95(C6), 9671-9678. https://doi.org/10.1029/JC095iC06p09671

Signell, R. P., \& List, J. H. (1997). Effect of wave-enhanced bottom friction on storm-driven circulation in Massachusetts Bay. Journal of Waterway Port Coastal And Ocean Engineering-Asce, 123(5), 233-239. https://doi.org/10.1061/(Asce)0733-950x(1997)123:5(233)

Snyder, R. L., Dobson, F. W., Elliott, J. A., \& Long, R. B. (1981). Array measurements of atmospheric pressure fluctuations above surface gravity waves. Journal of Fluid Mechanics, 102(1), 1-59. https://doi.org/10.1017/S0022112081002528

Sommerfield, C. K., \& Wong, K.-C. (2011). Mechanisms of sediment flux and turbidity maintenance in the Delaware Estuary. Journal of Geophysical Research, 116, C01005. https://doi.org/10.1029/2010jc006462

Styles, R., \& Glenn, S. M. (2000). Modeling stratified wave and current bottom boundary layers on the continental shelf. Journal of Geophysical Research, 105(C10), 24119-24139. https://doi.org/10.1029/2000jc900115

Styles, R., \& Glenn, S. M. (2002). Modeling bottom roughness in the presence of wave-generated ripples. Journal of Geophysical Research, 107(C8), 3110. https://doi.org/10.1029/2001jc000864

Sullivan, P. P., Mcwilliams, J. C., \& Melville, W. K. (2007). Surface gravity wave effects in the oceanic boundary layer: Large-eddy simulation with vortex force and stochastic breakers. Journal of Fluid Mechanics, 593, 405-452. https://doi.org/10.1017/S002211200700897x

Taylor, P. K., \& Yelland, M. J. (2001). The dependence of sea surface roughness on the height and steepness of the waves. Journal of Physical Oceanography, 31(2), 572-590. https://doi.org/10.1175/1520-0485(2001)031<0572:Tdossr $>2.0$. Co;2

Thornton, E. B., \& Guza, R. T. (1983). Transformation of wave height distribution. Journal of Geophysical Research, 88(C10), 5925-5938. https://doi.org/10.1029/JC088iC10p05925

Uchiyama, Y., McWilliams, J. C., \& Shchepetkin, A. F. (2010). Wave-current interaction in an oceanic circulation model with a vortex-force formalism: Application to the surf zone. Ocean Modelling, 34(1-2), 16-35. https://doi.org/10.1016/j.ocemod.2010.04.002

Wargula, A., Raubenheimer, B., \& Elgar, S. (2014). Wave-driven along-channel subtidal flows in a well-mixed ocean inlet. Journal of Geophysical Research: Oceans, 119, 2987-3001. https://doi.org/10.1002/2014JC009839

Warner, J. C., Armstrong, B., He, R. Y., \& Zambon, J. B. (2010). Development of a Coupled Ocean-Atmosphere-Wave-Sediment Transport (COAWST) modeling system. Ocean Modelling, 35(3), 230-244. https://doi.org/10.1016/j.ocemod.2010.07.010

Warner, J. C., Sherwood, C. R., Arango, H. G., \& Signell, R. P. (2005). Performance of four turbulence closure models implemented using a generic length scale method. Ocean Modelling, 8(1), 81-113. https://doi.org/10.1016/j.ocemod.2003.12.003 
Warner, J. C., Sherwood, C. R., Signell, R. P., Harris, C. K., \& Arango, H. G. (2008). Development of a three-dimensional, regional, coupled wave, current, and sediment-transport model. Computers \& Geosciences, 34(10), 1284-1306. https://doi.org/10.1016/j.cageo.2008.02.012 Whitney, M. M., \& Codiga, D. L. (2011). Response of a large stratified estuary to wind events: Observations, simulations, and theory for Long Island sound. Journal of Physical Oceanography, 41(7), 1308-1327. https://doi.org/10.1175/2011jpo4552.1

Winant, C. D. (2008). Three-dimensional residual tidal circulation in an elongated, rotating basin. Journal of Physical Oceanography, 38(6), 1278-1295. https://doi.org/10.1175/2007jpo3819.1

Wong, K. C., \& Garvine, R. W. (1984). Observations of wind-induced, subtidal variability in the Delaware Estuary. Journal of Geophysical Research, 89(C6), 10,589-10,597. https://doi.org/10.1029/JC089iC06p10589

Wu, J. (1982). Wind-stress coefficients over sea-surface from breeze to hurricane. Journal of Geophysical Research, 87(C12), 9704-9706. https://doi.org/10.1029/JC087iC12p09704 